\title{
An Innovative Ceramic Corrosion Protection System for Zircaloy Cladding
}

\section{Year 3 - 4th Quarter Report (+6)}

February, 2003

PROJECT FINAL REPORT

Includes Work Conducted Under a Six Month, No Cost Extension.

NERI Research Project

No. DE-FG03-99SF21882

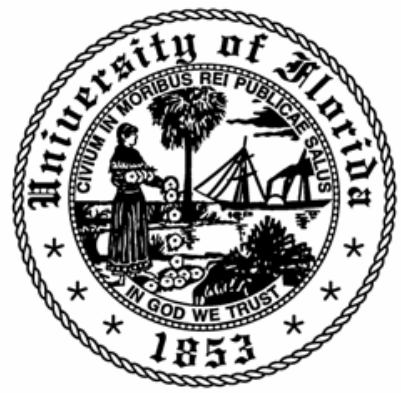

University of Florida

College of Engineering

Gainesville, FL 32611 


\title{
Report for Work Through June 30, 2002 \\ Including Work Conducted Under a Six Month, No Cost Extension.
}

\author{
Co-Principle Investigators: \\ Ronald H. Baney $<$ rbane@mse.ufl.edu> \\ Department of Materials Science \\ James S. Tulenko $\leq$ tulenko@ufl.edu $>$ \\ Department of Nuclear and Radiological Engineering \\ P.O. Box 118300 \\ Gainesville, Florida 32611-8300 \\ Tel: (352) 392-1401 \\ Fax: (352) 392-3380
}

Additional University of Florida Contributors to this Report:

Dr. D. Butt

Dr. P. Demkowicz

Dr. G. Fuchs

Dr. G. Schoessow

Mr. S. Bang

Mr. Y. Al-Olayyan

Mr. S. Park 


\section{Executive Summary}

This report is the final for NERI research project No. DE-FG03-99SF21882. It incorporates the result of the fourth quarter of year three, plus the effort that was conducted under a six month, no cost extension.

The operational lifetime of light water reactor (LWR) fuel is limited by thermal, chemical, and mechanical constraints associated with the operating conditions of the fuel rod assemblies. A primary limiting factor is the waterside corrosion of the zirconium alloy (Zircaloy) cladding that encases the uranium oxide pellets. Oxidation of the cladding in the high temperature, highpressure aqueous environment results in the continuous formation of a zirconium oxide layer that eventually begins to spall, degrading the clad integrity. Protective coatings applied to the Zircaloy cladding can drastically reduce this corrosion and degradation. The result of the protective coating is that the fuel can operate at significantly higher burnups, resulting in major benefits to plant safety and economics.

Research in the first two project years included the identification of suitable coating materials and the development of the appropriate deposition techniques. As a result of these efforts, current research in the final eighteen months focused on alumina, silicon carbide, and diamondlike carbon (DLC) as coating materials. Studies in the current nine month period (Y3-Q4 + 6 mo.) have included thermal stability tests of silicon carbide coatings, deposition and autoclave studies of sputtered alumina coatings, and electrochemical testing of alumina coatings prepared by controlled oxidation of thin aluminum films.

The thermal stability of silicon carbide coatings on Zircaloy substrates has been investigated. The coatings were deposited by plasma assisted chemical vapor deposition (PACVD) of methylchlorosilane precursors onto substrates with various chemical and mechanical surface treatments. Samples were heated to $350^{\circ} \mathrm{C}$ for $500 \mathrm{~h}$ in a vacuum and examined for comparison with unheated samples. SEM observation revealed no change in the surface morphology of heattreated samples. Scratch tests, conducted to assess film adhesion, indicated increases in the critical load for heated samples. The films did not survive autoclave exposure $\left(350^{\circ} \mathrm{C}, 3000\right.$ psig). The observation of the presence of small amounts of residual chlorine reported in Y3-Q4 report suggested a possible failure mode in the autoclave tests. In the final six months, substrates were coated with $\mathrm{SiC}$ by $\mathrm{PACVD}$ with a non chlorine-containing precursor, trimethylsilane. These SiC coated Zirc-4 substrates also failed to survive in the autoclave environment. It was reported in $\mathrm{Y} 3-\mathrm{Q} 3$ that no changes were observed in the $\mathrm{SiC}$ coatings upon thermal treatment alone and that the coatings showed excellent adhesion as measured by scratch testing. Current studies suggest that partial oxidation of the $\mathrm{SiC}$ coatings in the autoclave environment leads to stresses developing in the coating due to density differences in the $\mathrm{SiC}$ and the resulting $\mathrm{SiO}_{2}$. This condition leads to buckling and ultimately failure of the $\mathrm{SiC}$ protective film.

Alumina coatings were prepared using radio frequency sputtering. Coating thicknesses of $1 \mu \mathrm{m}$ were achieved. Autoclave exposure $\left(350^{\circ} \mathrm{C}, 3000 \mathrm{psig}\right)$ resulted in the deterioration of these films. Sputter deposited alumina coatings were annealed at temperatures ranging from 450 $650^{\circ} \mathrm{C}$ in order to realize an increase in hydrothermal stability. After autoclave exposure, the 
surfaces of the annealed sample were covered with what appear to be hydrothermally grown crystallites, which have been identified as boehmite, $(\mathrm{AlOOH})$.

Electrochemical corrosion studies were performed on alumina coatings that have previously been prepared by controlled oxidation of aluminum thin films on zircaloy through surface alloying. The results indicated a significant difference in corrosion behavior of the coatings based on the temperature of the oxidation step. Samples heated at $500^{\circ} \mathrm{C}$ exhibited corrosion behavior similar to that of the bare Zircaloy substrate. Samples that underwent a two-step heat treatment at $650^{\circ} \mathrm{C}$ and $500^{\circ} \mathrm{C}$, however, exhibited good corrosion resistance.

An economic analysis of a potential process for coating full length Zircaloy-4 clad tubes with $\mathrm{SiC}$ by a PACVD process was conducted by MER Corporation as one task in this NERI research effort. The analysis showed that 1.5 million tubes per year could be coated for a delivery cost of $\$ 42.16$ per tube.

This work is being prepared for publication. One report is in draft form and two others are in preparation. 


\section{Table of Contents}

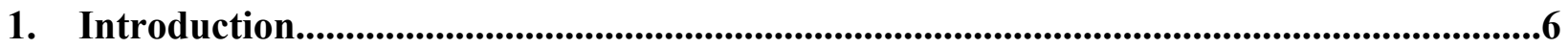

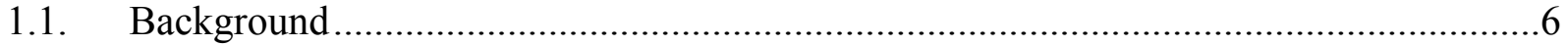

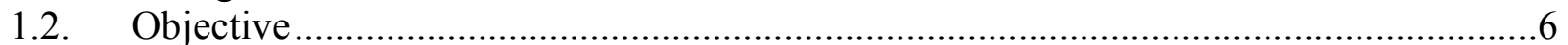

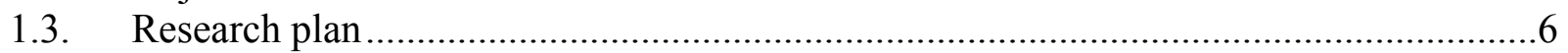

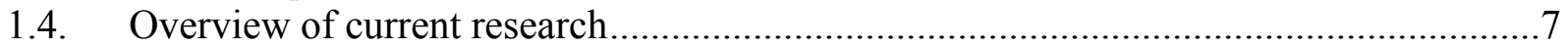

2. Thermal stabilization of $\mathrm{SiC}$ coated samples .............................................................................8

2.1. Thermal treatment and scratch test results..................................................................

2.2. Characterization of $\mathrm{SiC}$ coatings after autoclave test.................................................10

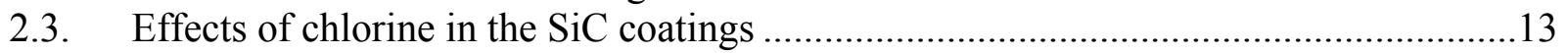

2.4. Measurement of ultimate shear strength of SiC/Zirc-4 interface. .................................15

2.5. Effect of hydrocarbon ion implantation the mechanical properties...............................19

2.6. Non chlorine-containing $\mathrm{SiC}$ Failure mechanism in autoclave ...................................21

3. Alumina coatings deposited by radio-frequency (RF) sputtering and by surface alloying with aluminum metal followed by oxidation ...............................................................25

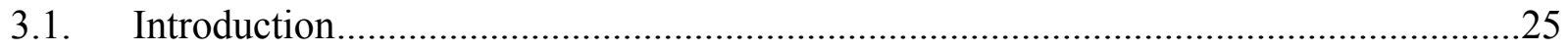

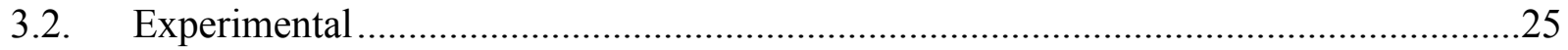

3.3. Results and discussion for the $\mathrm{Al}_{2} \mathrm{O}_{3}$ sputter coated samples ....................................26

3.4. Electrochemical corrosion tests in $1000 \mathrm{ppm}$ boric acid solution of alumina coated Zirc-4 formed by surface alloying with aluminum followed by oxidation .........32

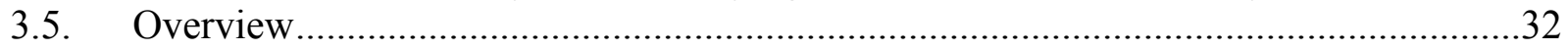

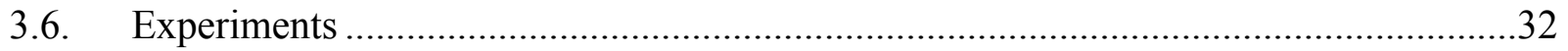

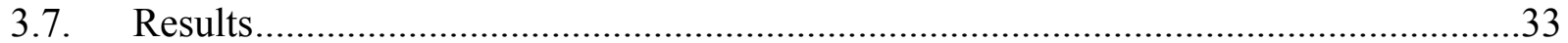

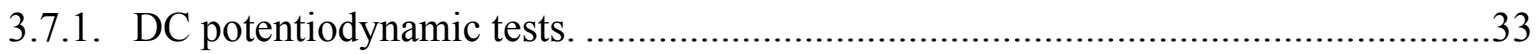

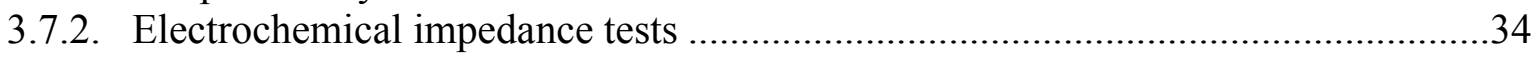

4. Economic analysis of a potential commercial process for coating full length Zircaloy-4 clad tubes with SiC 


\section{Introduction}

\section{Background}

One of the major contributors to the limits of high burnup for nuclear fuel is failure of the zirconium alloy clad due to oxidation. This corrosion leads to spalling of the zirconia layer formed on the clad surface leading to failure at the point of spallation. The formation of oxide layers on many metals such as aluminum and ceramics such as silicon carbide can serve as a barrier for oxygen transport to the virgin substrate. As the oxide layer increases in thickness a parabolic rate law is followed which results in a decreasing rate of oxidation of the substrate. This oxide layer serves to "passivate" the metal. The rate relationships for zirconium are more complex. As the thickness of the oxide layer increases, stresses build up in the oxide layer due to density differences between the oxide and the zirconium metal. This gives rise to a change in structure and instability in the mechanical properties of the zirconium oxide layer. The approach in this research effort is to form non-growing layers of coatings on the zirconium clad which can serve the same function as native oxides in passivating the clad. Additionally, the coatings will also serve to protect the cladding from fretting failure, a very positive secondary effect.

\section{Objective}

The objective of this NERI project was to develop ceramic corrosion protection systems for Zircaloy clad for use in light water reactors (LWR) that will allow significantly higher burnups resulting in major benefits in plant safety and plant economics.

\section{Research plan}

The major technical challenge for coating a metal with a ceramic protection system is to develop a bond between the low thermal expansion ceramic coating and the more ductile, high thermal expansion metal substrate that will enable the coating to maintain a protective layer in the hydrothermal environment of a PWR reactor. The stability, interface, and properties of several ceramic coatings on Zircaloy were examined to select the best combination(s) of coating and processing. Strategies followed to address this challenge included: (1) investigation of a range of coating materials including $\mathrm{SiC}, \mathrm{Al}_{2} \mathrm{O}_{3}$, and diamond-like carbon (DLC); (2) investigating the effect of processing temperatures; (3) investigating the use of a compliant interlayer to relieve expansion mismatch stresses; and (4) investigating the effects of surface topography or roughness. In the first year criteria were defined for screening and selecting ceramic coatings based upon their impact upon reactor performance and silicon carbide, alumina, and diamond like carbon became prime candidates. Coating process studies were begun along with tests to evaluate the efficacy of the different ceramic protection systems. These included electrochemical corrosion testing, stability in thermal and hydrothermal environments 


\section{Overview of current research}

This report presents research performed in the $4^{\text {th }}$ Quarter of Year 3 and work continued under the 6 month no cost contract extension.

The thermal stability of silicon carbide coatings was investigated in Y3-Q4. The preparation of SiC coatings by plasma assisted chemical vapor deposition (PACVD) was discussed in previous reports. Coatings were deposited on Zircaloy-4 substrates that had been prepared with a number of different surface treatments, including polishing to various surface finishes. The thermal stability tests involved heating samples to $350^{\circ} \mathrm{C}$ for 500 hours in a vacuum. Scratch tests were performed on the heat-treated coatings to assess adhesion. Autoclave studies were also performed on the samples to determine the coatings' hydrothermal durability.

Alumina coatings of $1 \mu \mathrm{m}$ thickness were prepared by radio frequency sputtering. The coatings were annealed at temperatures between $450-650^{\circ} \mathrm{C}$ in an attempt to improve the durability of the coatings. Both annealed and as-deposited coatings were tested in an autoclave to determine their hydrothermal stability.

The corrosion behavior of alumina coatings also prepared by surface alloying Zirc-4 specimens by coating with a thin film of the aluminum by electron beam evaporation followed by controlled oxidation of aluminum films and described in previous reports, Y3-Q2 and Y3-Q3, was investigated using electrochemical methods. 


\section{Thermal stabilization of $\mathrm{SiC}$ coated samples}

\section{Thermal treatment and scratch test results}

This experiment was carried out in order to study the effect of temperature on the adhesion of $\mathrm{SiC}$ coatings on zircaloy samples.

Seven Zircaloy-4 (Zr-4) substrates were chemically and mechanically pre-treated to give a variety of surface conditions. The substrate treatments were as follows:
A. As-received
B. 600 grit polishing
C. 240 grit polishing
D. Pickled $(25-50 \%$ nitric acid $(70 \% \mathrm{w} / \mathrm{w}), 2-5 \%$ hydrofluoric acid $(49 \% \mathrm{w} / \mathrm{w})$ and water.
E. Grit blasted (grit $40-60$ by glass beads)
F. Pre-oxidized (polished to 240 grit, heated to $1200^{\circ} \mathrm{C}$ for 10 minutes and air cooled).

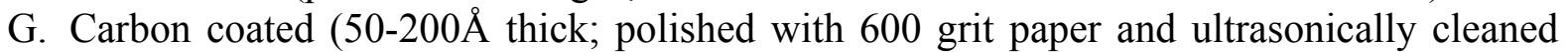 before carbon coating)

Silicon carbide coatings ( $\sim 1 \mu \mathrm{m}$ thickness) were applied to the substrates by plasma assisted chemical vapor deposition (PACVD). The samples were then encapsulated under vacuum as shown in Figure 1 to avoid any interaction with the atmosphere. The samples were heated to $350^{\circ} \mathrm{C}$ for 500 hours in a box furnace.

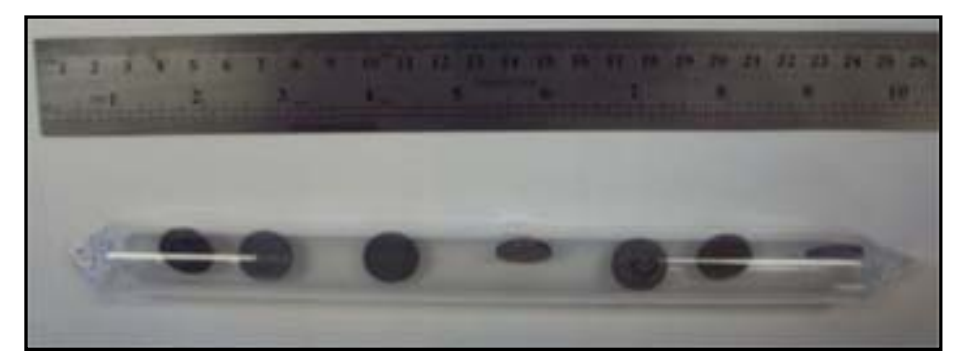

Figure 1. Zircaloy samples coated with $\mathrm{SiC}$ and encapsulated under vacuum for thermal stability test.

SEM characterization of the heat-treated surfaces as shown in Figure 2 indicates no change in the surface morphology of the coatings.

Scratch tests were performed on three of the thermally treated samples (600 grit polished, 600 grit polished and pre-oxidized sample). The tests consist of the generation of scratches with a spherical stylus (generally Rockwell C diamond, tip radius $200 \mu \mathrm{m}$ ) that is drawn at a constant speed across the coated substrate, under either constant or progressive loading at a fixed rate. For progressive loading, the critical 
load $\left(\mathrm{L}_{\mathrm{c}}\right)$ is defined as the smallest load at which a recognizable failure occurs; for the constant loading mode, the critical load corresponds to the load at which a regular occurrence of such failure along the track is observed. Four to five scratches were made on each sample. The test conditions for scratch analysis are given in Table 1. For each measurement the acoustic emission signal (AE), the tangential force $(\mathrm{Ft})$, and the penetration depth are recorded versus the normal load.

Figure 3 shows the critical force, Lc, at which damage of the coating occurs for each sample. The results show much higher adhesion strength for samples after heat treatment compared to values before heat treatment. The pre-oxidized sample has been excluded from the results because of the thick and cracked oxide film.

\begin{tabular}{lc}
\hline Loading range & $0-15 \mathrm{~N}$ \\
Loading rate $(\mathrm{dL} / \mathrm{dt})$ & $15 \mathrm{~N} / \mathrm{min}$ \\
Scratch Length & $3 \mathrm{~mm}$ \\
Scratching speed $(\mathrm{dx} / \mathrm{dt})$ & $3 \mathrm{~mm} / \mathrm{min}$ \\
AE sensitivity, $\mathrm{S}_{\mathrm{AE}}$ & 9 \\
Indenter radius & $200 \mu \mathrm{m}$ \\
Diamond reference number & $\mathrm{L}-205$ \\
\hline
\end{tabular}

Table 1. Test conditions for scratch analysis.

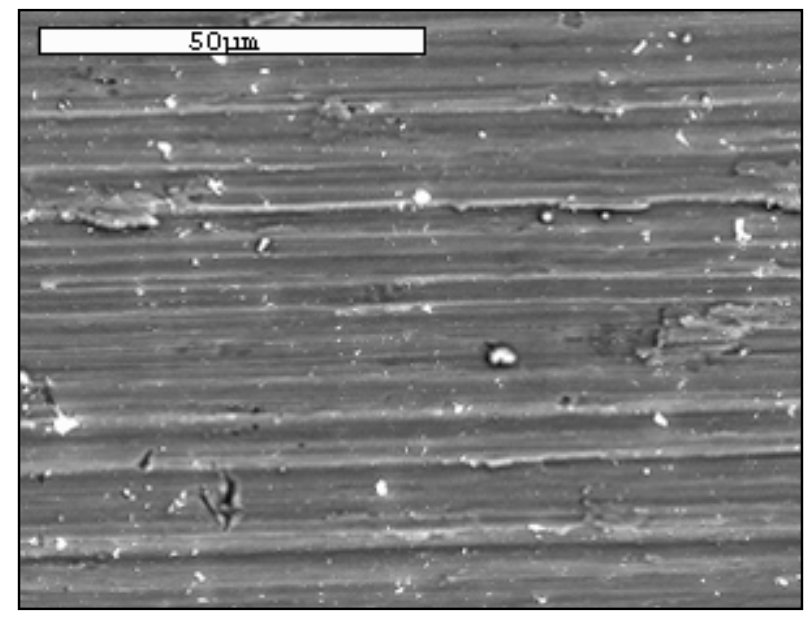

Figure 2. SEM micrograph of a SiC coating after thermal treatment in a vacuum. 


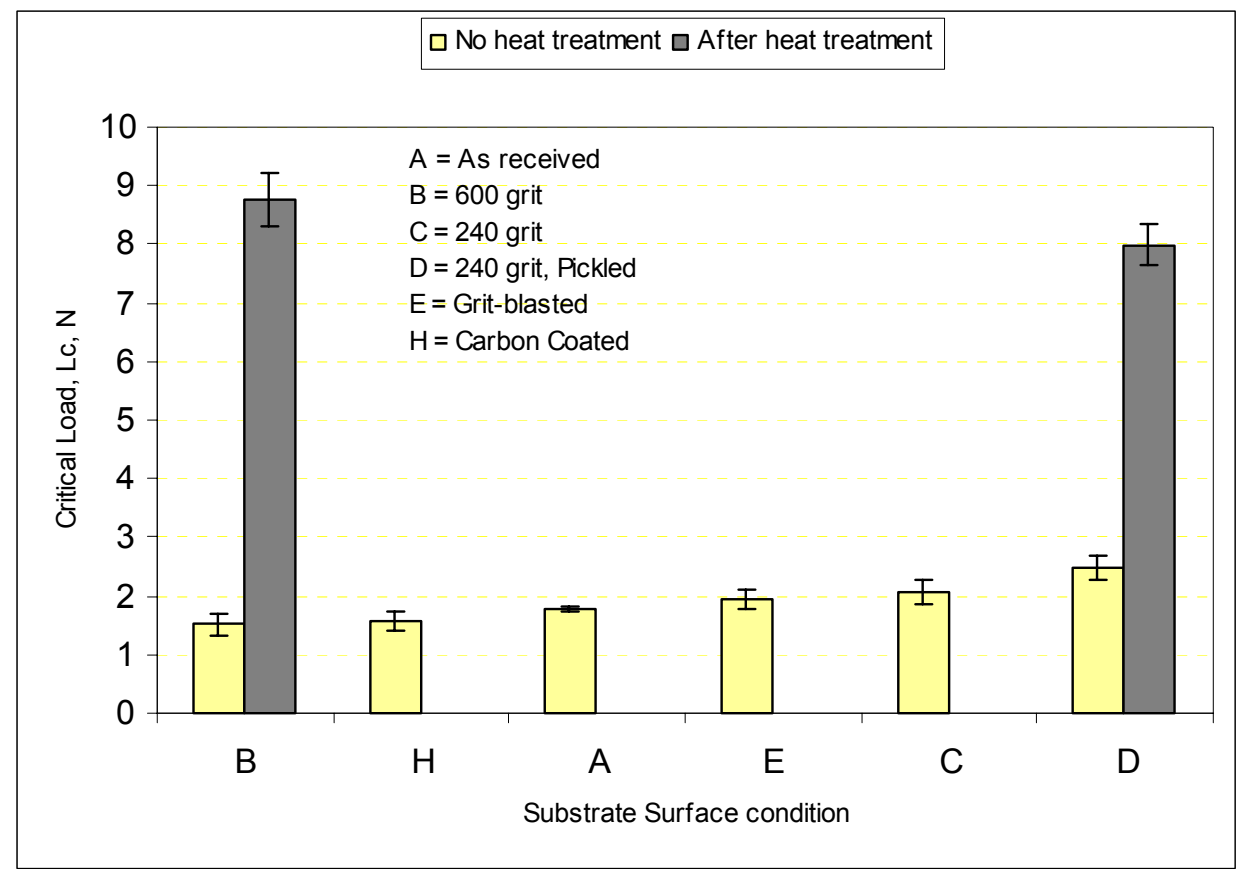

Figure 3. Scratch test results of the two samples (B and D) after thermal treatment compared to the previous results of samples before heat treatment.

It was found that the thermal spray process generates significant residual stresses in the coatings. These residual stresses are detrimental to the bonding strength of the coating/ substrate system and are therefore expected to influence the value of critical load, Lc, necessary to produce a crack at the interface. The higher adhesion strength found in heat-treated samples could be attributed to the relief of residual stresses in the coatings.

\section{Characterization of $\mathrm{SiC}$ coatings after autoclave test}

Zircaloy samples coated with $1 \mu \mathrm{m}$ thick SiC films were tested in the autoclave at $350^{\circ} \mathrm{C}$ and 3000 psi for 24 hours.

Microscopic and SEM examination of the samples after autoclave indicated that SiC coatings were removed from almost all samples. Only one sample (600 grit polished) was found to have some areas of coatings left.

Figure 4a shows the remaining pieces of the coating film in a large bare area of the Zircaloy substrate. Figure $4 \mathrm{~b}$ shows how the film starts to detach from the substrate. A backscattered SEM image is shown in Figure 5, which indicates clearly the difference between the two areas based on the elemental composition. 
Figure 6 is an EDX map of an area on the sample surface that includes part of the coating that remained on the surface after autoclave exposure. The oxygen level present in the $\mathrm{SiC}$ film as shown is much higher than that on the bare substrate.

A comparison of weight loss between samples exposed to thermal treatment and those exposed to the autoclave environment is shown in Figure 7. It shows that there is almost no effect of high temperature treatment on the loss of the film compared to the corrosion attack in the autoclave.
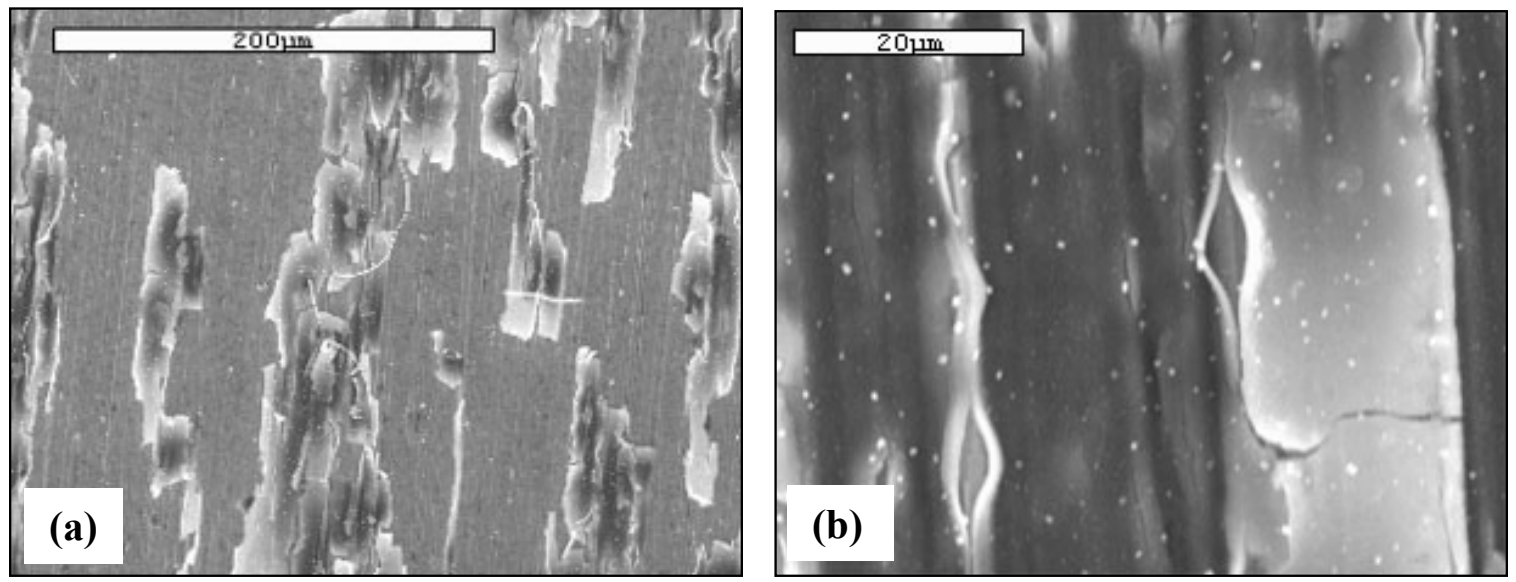

Figure 4. SEM micrographs of the $\mathrm{SiC}$ coated surface of a Zircaloy substrate (600 grit polished) after autoclave exposure. Pieces of SiC coating (a) remaining on the zircaloy substrate; (b) sites where the coating is beginning to fracture and detach from the substrate.
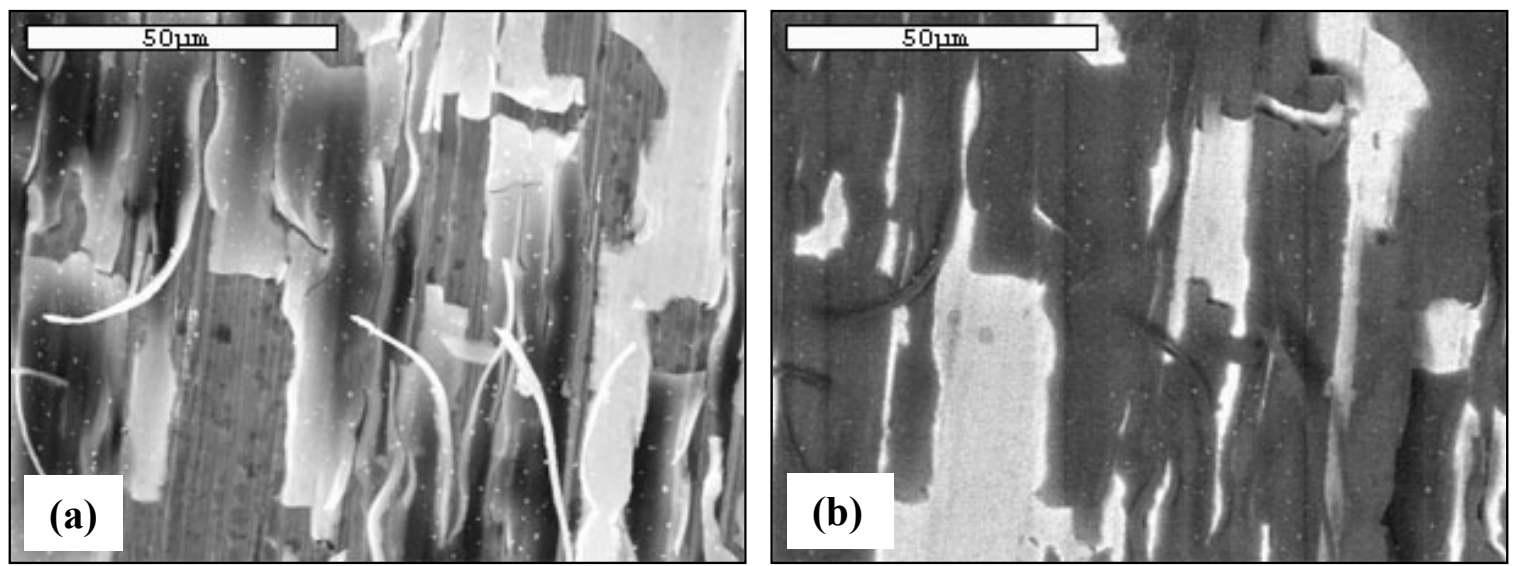

Figure 5. SEM micrographs of the $\mathrm{SiC}$ coated surface of a

Zircaloy substrate (600 grit polished) after autoclave exposure. (a)

Secondary electron image and (b) backscattered electron image. 

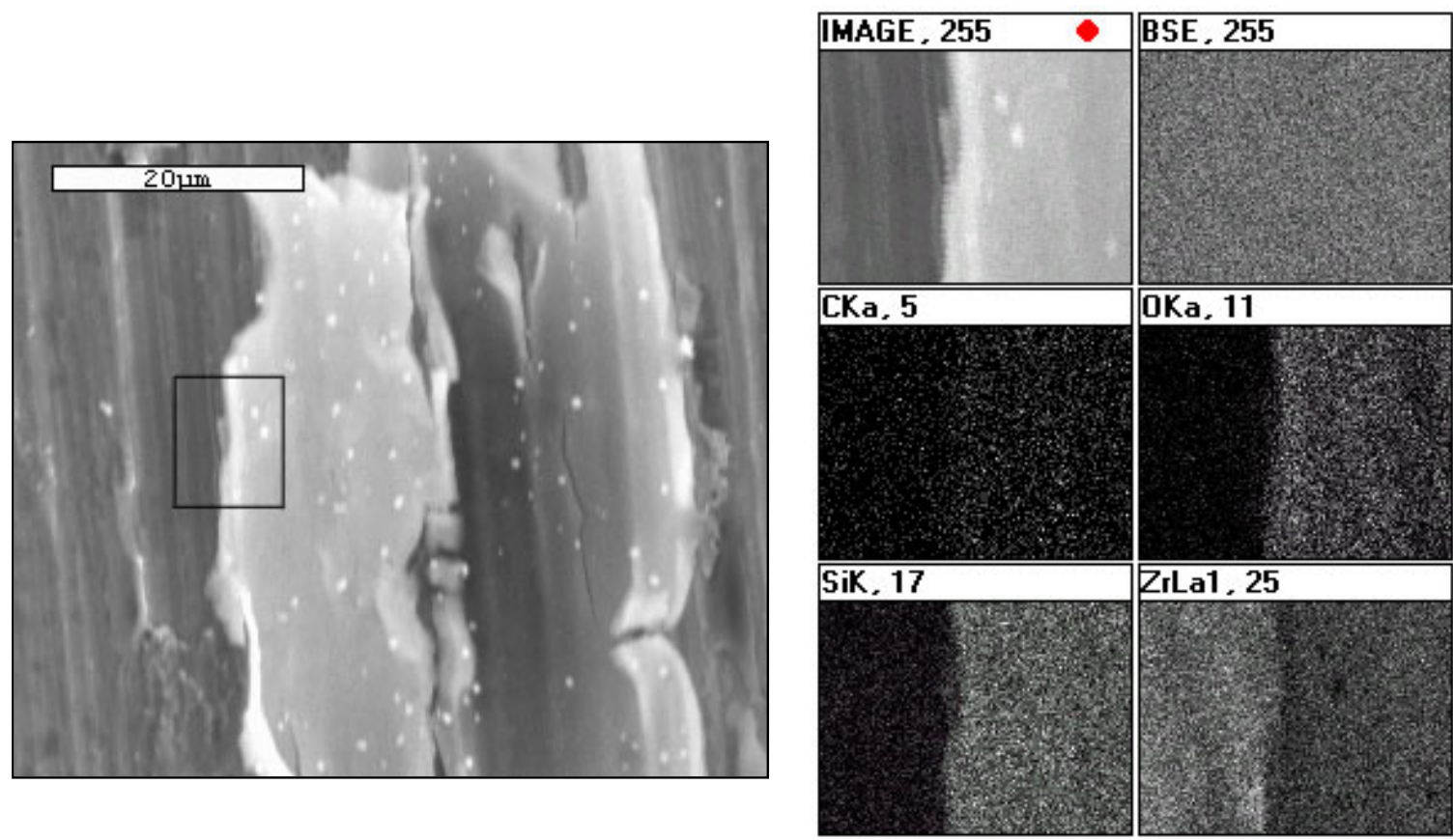

Figure 6. SEM/EDX mapping of the selected area indicated on the left, including a piece of remaining film (light region) and the bare zircaloy substrate (dark region).

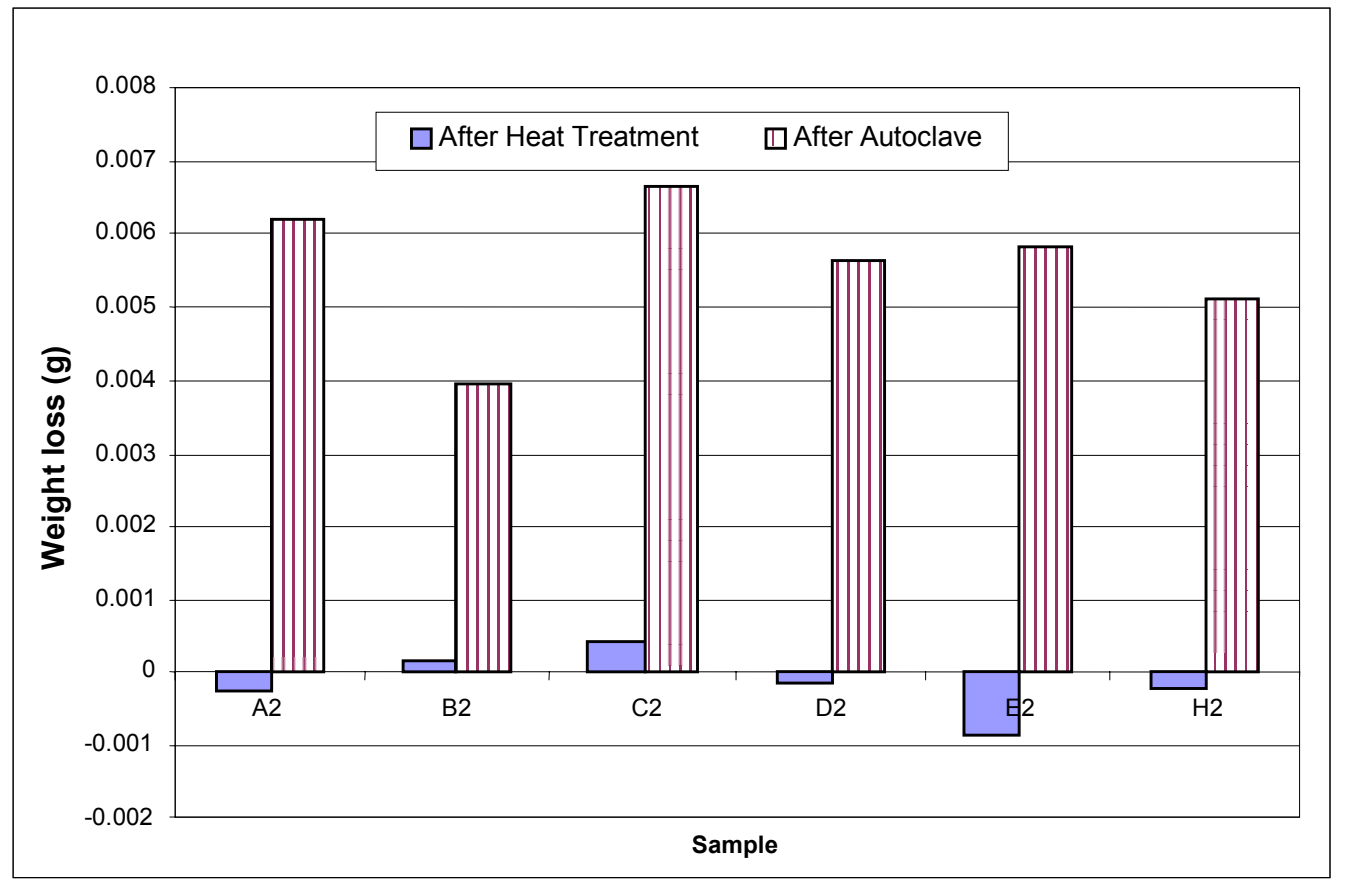

Figure 7. Weight loss (in grams) of the coated samples after thermal stability test and after autoclave. 


\section{Effects of chlorine in the $\mathrm{SiC}$ coatings}

In report Y3-Q3 we reported that our PACVD processed SiC prepared by MER Corporation contained chlorine presumably originating from their proprietary process involving chlorosilanes. It seemed reasonable to assume that the hydrothermal instability of the $\mathrm{SiC}$ coatings reported above might arise from hydrolysis reactions involving the chlorine. As a result, new Zircaloy-4 samples were coated with a non chlorine-containing precursor, trimethylsilane.

To determine the effect of chlorine in the previous coating tests on the stability of SiC coatings in autoclave, six zircaloy samples coated with $\mathrm{SiC}$ using trimeyhylsilane (TMS) as the precursor. Three samples were coated with approximately 1.5-micron thick film. The other three samples were coated with approximately 3-micron thick film.

SEM characterization shows some cracks on the 1.5 micron film coatings as shown in Fig. 8(a). The 3 microns thick films show better surface finish with no cracks or defects as shown in Fig. 1(b). The strong peak of $\mathrm{Zr}$ from EDX spectrum shown in Fig. 9 compared to that for 3 microns could be attributed to the presence of cracks in addition to the difference in film thickness.

To determine the stability of the SiC coatings at hydrothermal conditions, samples of 1.5 micron and 3 microns film thickness were placed in an autoclave. The test conditions were $350^{\circ} \mathrm{C}$ temperature and 3500 psi pressure for 24 hours.

Fig. 10 and 11 shows the SEM images and EDX analysis of SiC coatings after the autoclave test. No SiC coatings were observed or detected after the autoclave tests for all samples.
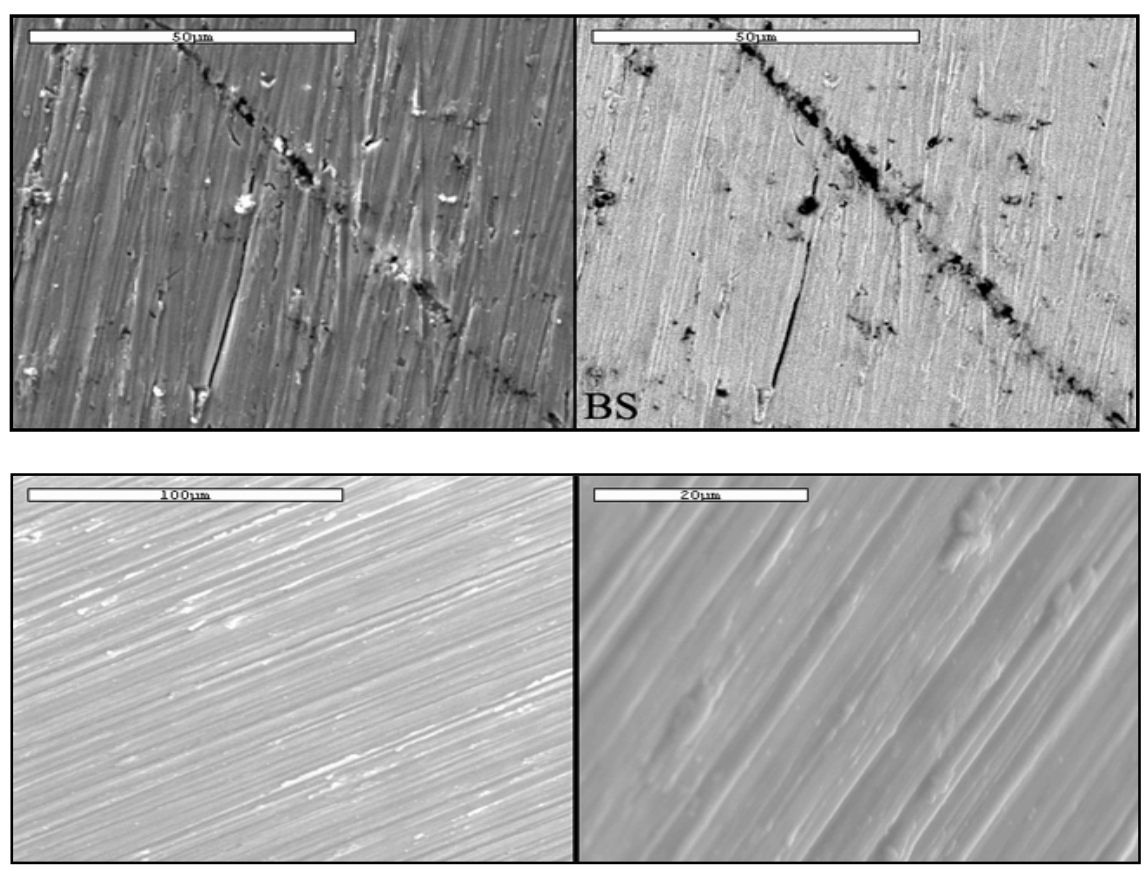

Fig 8. SEM images for: (a) 1.5 micron thick $\mathrm{SiC}$, (b) 3 microns thick $\mathrm{SiC}$ film on $\mathrm{Zr}-4$ substrate 

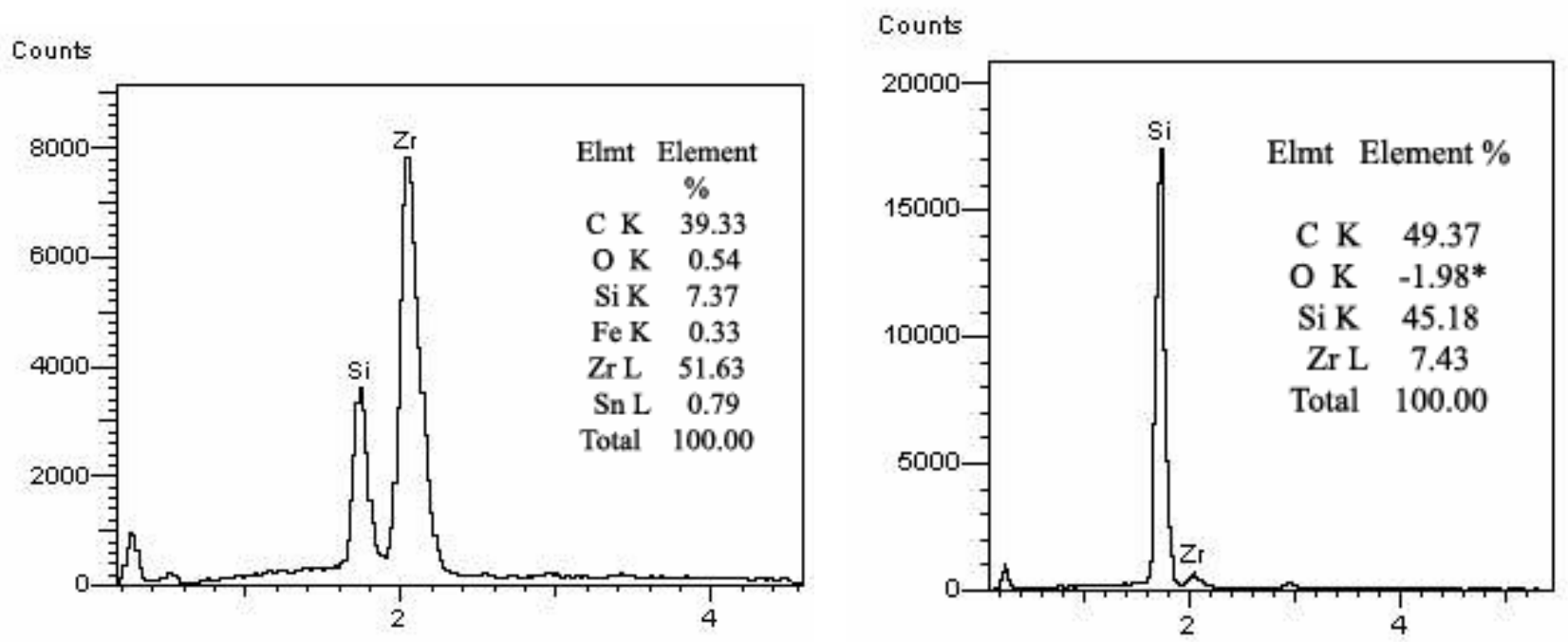

Fig. 9. EDX spectrum for: (a) 1.5 micron SFefinke'(b) 3 microns SiC film, on Zr-4 substrateietgy (kev)
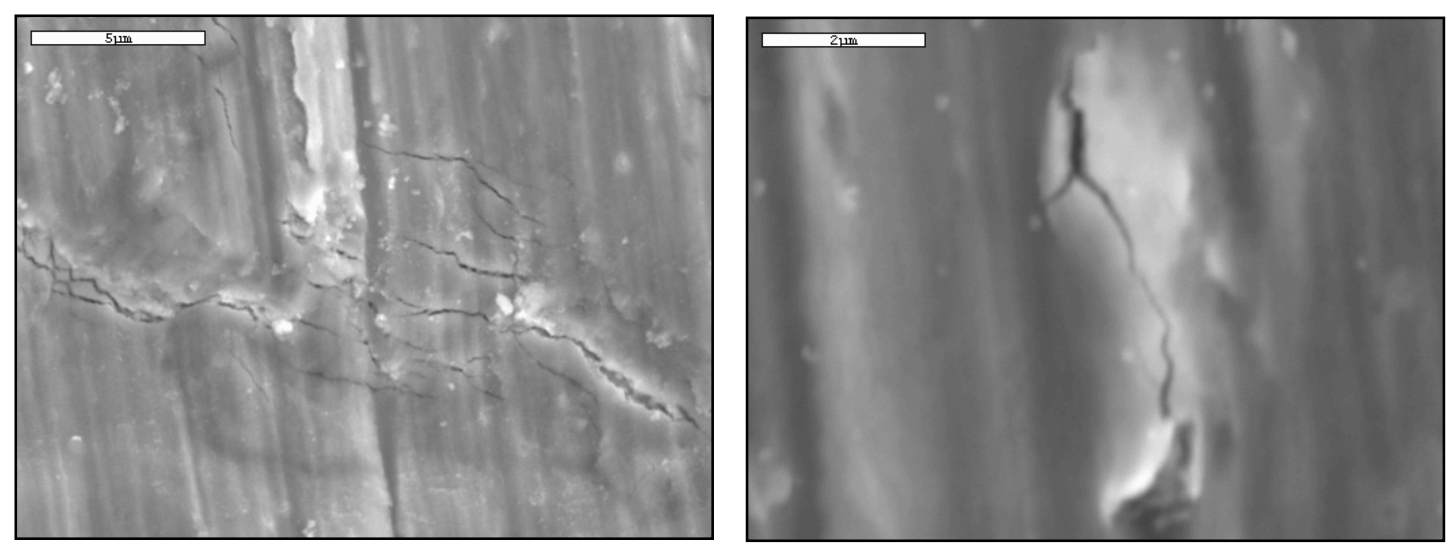

Fig. 10. SEM images for: 3 microns thick SiC film on Zr-4 substrate after autoclave test.
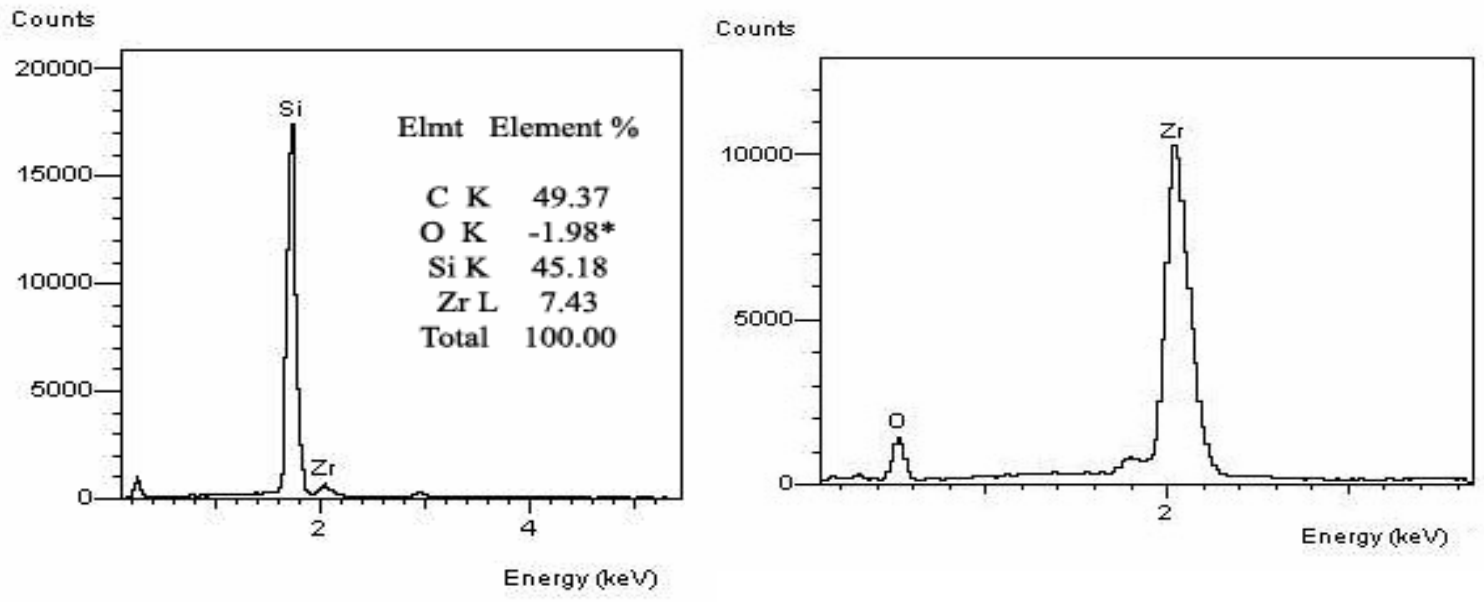

Fig. 11. EDX for 3-micron thick SiC film on Zr-4 substrate: (a) before autoclave, (b) after autoclave test. 
To determine the effect of thermal stresses on the $\mathrm{SiC}$ coatings, a sample was tested in the box furnace for the same time and temperature that been used in autoclave test. It can be seen from Fig. 12 that the coating was not affected by thermal stresses compared to hydrothermal effects.

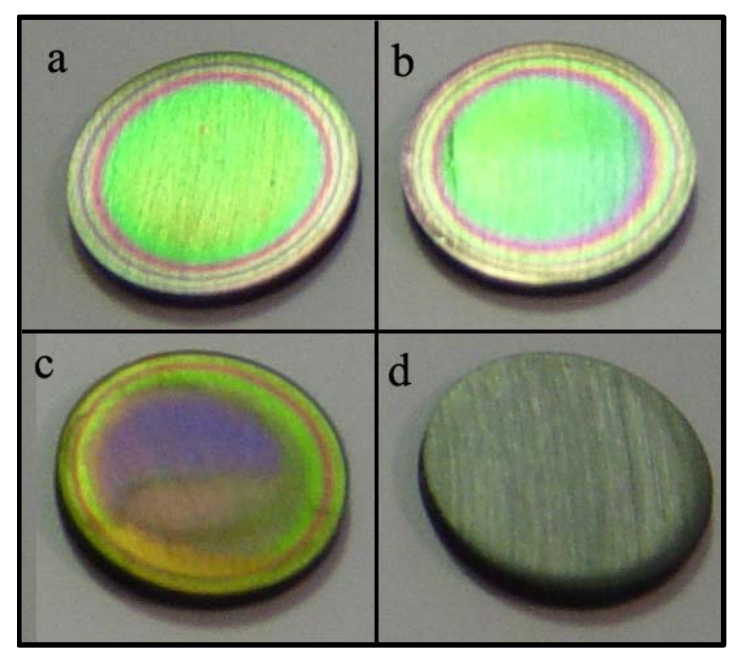

Fig. 12. Photograph shows the variations in the coating surfaces:

a: Coated sample (as-received) $-1 \mu \mathrm{m}$ thickness $\mathrm{SiC}$ film on $\mathrm{Zr}-4$ substrate

b: After $24 \mathrm{hrs}$ in box furnace $@ 350 \mathrm{C}$

c: Coating Partially failed in autoclave (24hrs, 3000psi @350C)

d: Coating totally failed in autoclave (24hrs, 3000psi @350C)

\section{Measurement of ultimate shear strength of SiC/Zirc-4 interface.}

The ultimate shear strength of a SiC/Zirc-44 interface has been measured by the periodic cracking method. As the metal is plastically stretched, the ceramic film develops cracks that are oriented transverse to the pulling direction. The Dog bone samples of Zirc-4 density of the cracks (the number per unit length) increases as more and more plastic strains are applied to the metal substrate. Eventually, the crack density reaches a constant value and is not influenced by further plastic deformation of the metal. The ultimate shear strength of the metal-ceramic interface is related to the tensile fracture strength of the ceramic film and the largest spacing between the cracks; both of these quantities are measured in this technique.

Flat Dog bone strips of Zirc-4, 0.063 in thick x 0.25 wide $\times 1.025$ in gauge length were prepared and polished from two sides to 600 grit followed by ultrasonic cleaning (see Figure 13). Specimens were sent to MER and coated by 1.5 thick $\mathrm{SiC}$ film using the trimethylsilane precursor. 
The specimens were pulled uniaxially in tensile test machine and tensile-strain curves were generated, as shown in Figure 14. Tensile tests were paused at different levels of strains to measure the crack spacing.

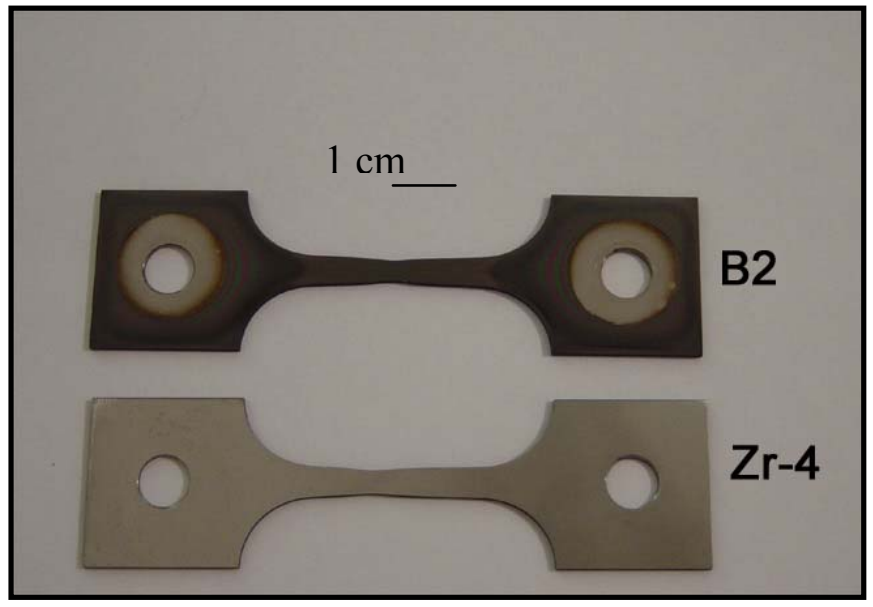

Fig. 13. Two dog bones samples. Tensile test paused at 30\%strain. B2: Zr-4 Coated with SiC $3 \mu \mathrm{m}$ thickness. Zr-4: Zircaloy specimen with no coating.

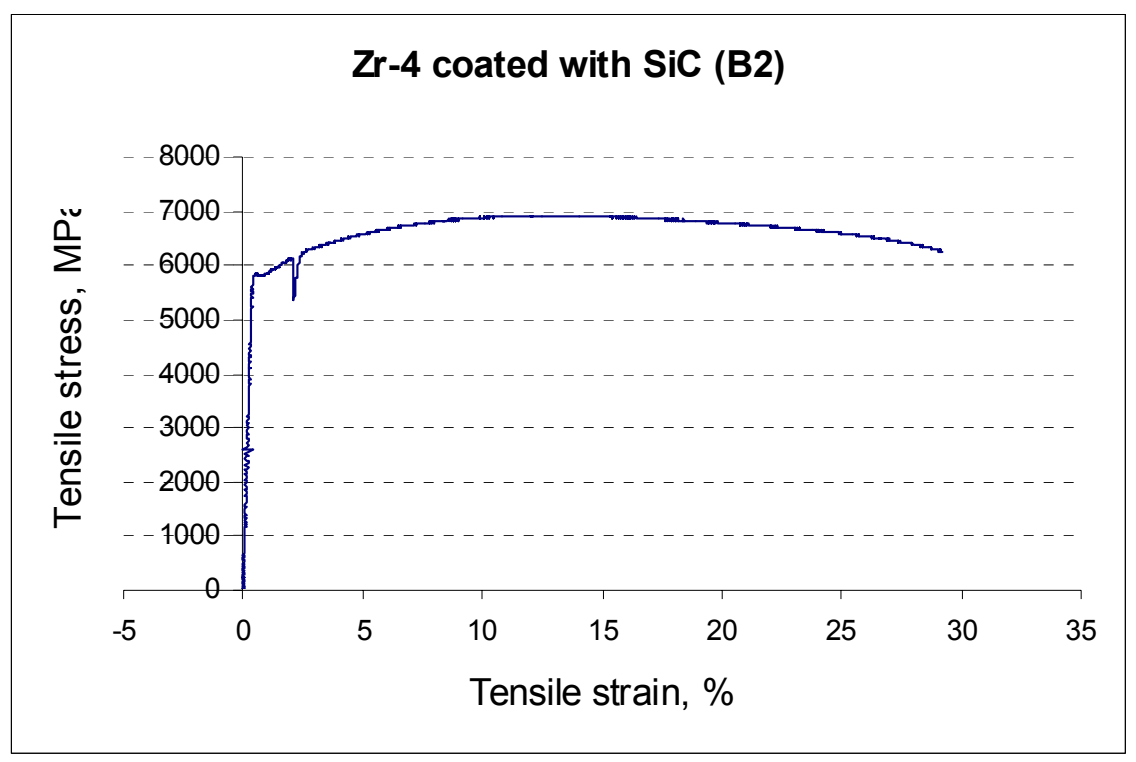

Fig. 14. Tensile test of $\mathrm{Zr}-4$ coated with 1.5 micron $\mathrm{SiC}$ film. The test was paused at $30 \%$ strain to measure crack spacing. 


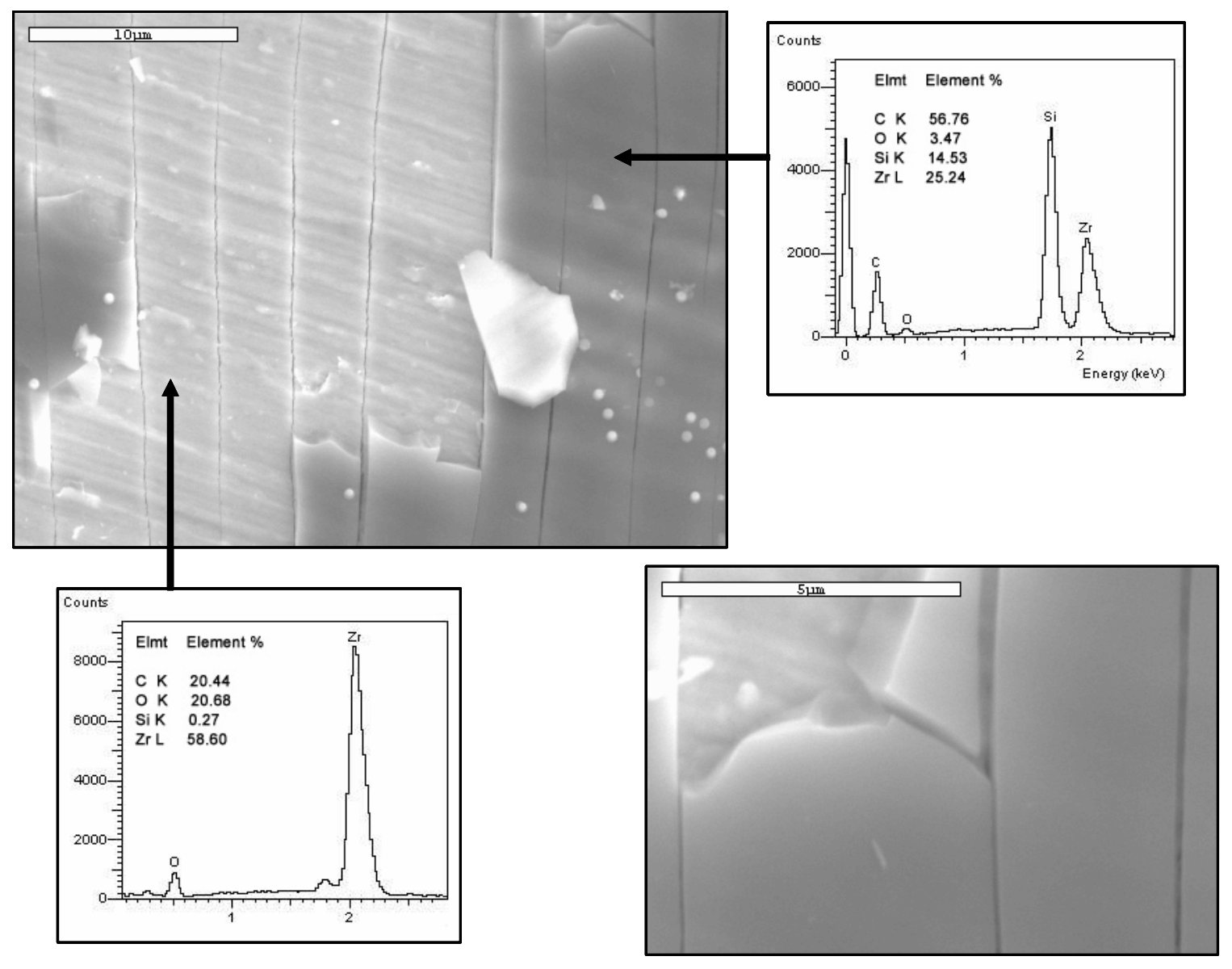

Fig. 15. SEM images and EDX spectrum of a cracked coating after $30 \%$ strain.

SEM and EDX results show a presence of an oxide layer underneath SiC film as shown in Fig. 15. Table 2 confirms the high percentage of oxygen detected on the area underneath SiC film. The oxide layer

\begin{tabular}{|c|l|l|l|l|l|}
\hline Sample & Area & $\mathrm{Zr}$ & $\mathrm{Si}$ & $\mathrm{C}$ & $\mathrm{O}$ \\
\hline Zr-4 (As received) & & 81 & 0.2 & 18 & 0.02 \\
\hline \hline $\begin{array}{c}\text { Coated } \\
\text { Sample (B2\&B3) }\end{array}$ & Film & 25.24 & 14.53 & 56.76 & 3.47 \\
\cline { 2 - 6 } & Detached area & 58.6 & 0.27 & 20.44 & 20.86 \\
\hline
\end{tabular}

Table 2. EDX quantitative elemental analysis of $\mathrm{Zr}-4$ surface and SiC coatings after tensile test. 

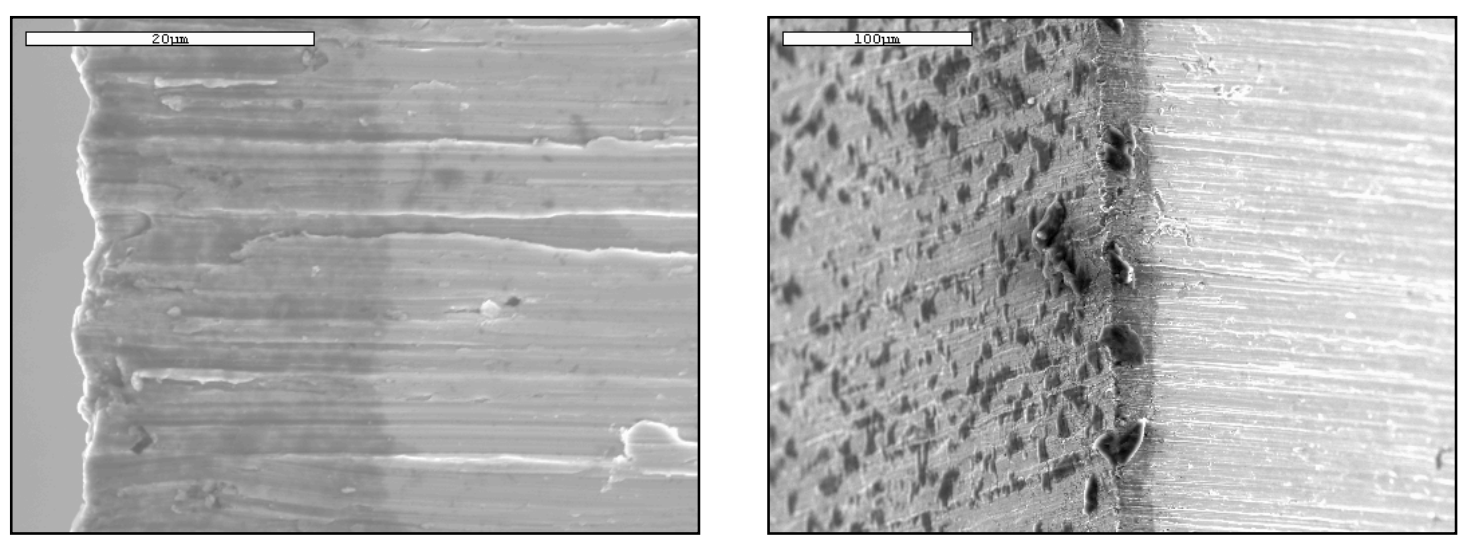

Fig. 16. SEM of cross section area of coated dog bone after $30 \%$ strain.
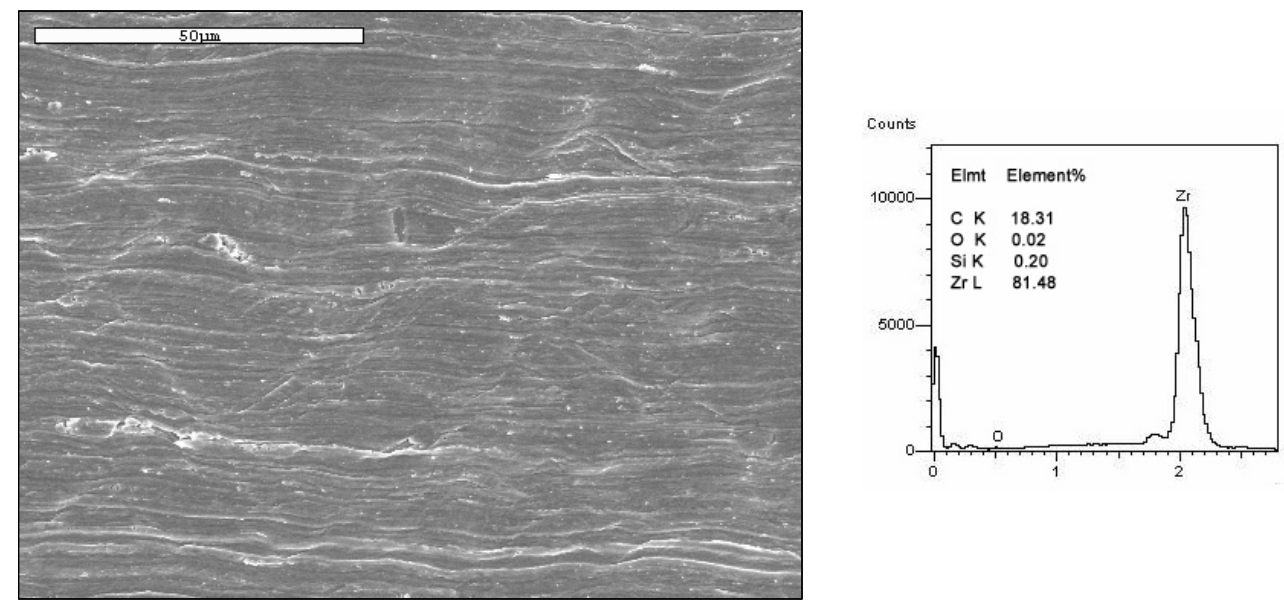

Fig. 17. SEM and EDX spectrum of Zr-4 with no coating after $30 \%$ strain.

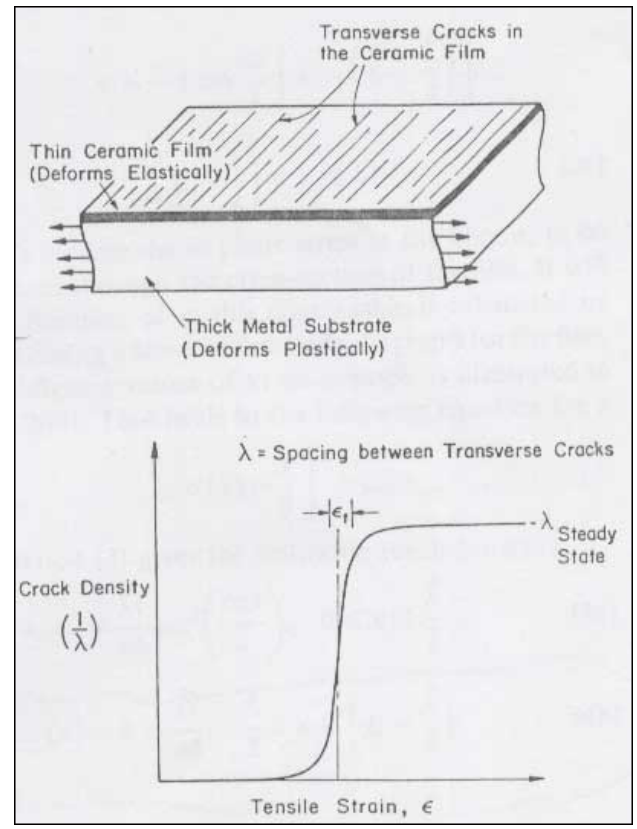

Figure 18. Illustration of the experimental technique (top). 
A typical schematic of the increase in crack density in the ceramic film with the strain applied to the metal substrate (bottom). Samples are being now analyzed for crack spacing at different strain levels to calculate the ultimate shear strength of the interface.

\section{Effect of hydrocarbon ion implantation the mechanical properties}

Various techniques are currently used to enhance the adhesion between ceramic thin films and metal substrates. Ion implantation has been used for long time to increase the adhesion strength of thin films to their substrates in a metal ceramic system. This process was found to create a graded interface between DLC and metal substrate, which leads to good film substrate adhesion. This work was made to investigate the effect of hydrocarbon implantation on the mechanical properties such as tensile strength, ductility and hardness of the Zirc-4 substrate.

Flat Dog bone strips of Zirc-4, 0.063 in thick x 0.25 wide $x 1.025$ in gauge length were prepared and polished from two sides to 600 grit followed by ultrasonic cleaning. The specimens were sent outside for hydrocarbon implantation. The specimens were pulled uniaxially in tensile test machine and tensile-strain curves were generated. Cross sections were prepared by electrodischarge machine followed by polishing to $0.3 \mu \mathrm{m}$ and ultrasonically cleaned. In order to measure the change in the hardness throughout the thickness, an indentation tests were made in the cross section surface with $0.15 \mu \mathrm{m}$ distance between each two indents as shown in Fig18.

The Vickers micro hardness tests were also made on untreated and treated Zirc-4 samples for various applied loads.

Fig. 19 shows the tensile test result for treated and untreated Zirc-4 samples. It can be observed that the treated samples have much lower ductility and higher tensile strength than the untreated samples. Fig. 20 shows the micro hardness data through the cross section of treated and untreated

samples. It can be observed that the micro hardness decreases as we move away from the treated surface

For the micro hardness test of the surface normal to the implantation, it can be observed from Figure 21 that the micro hardness decreases with increasing load, indicating that a harder region has formed in the near-surface layer. 


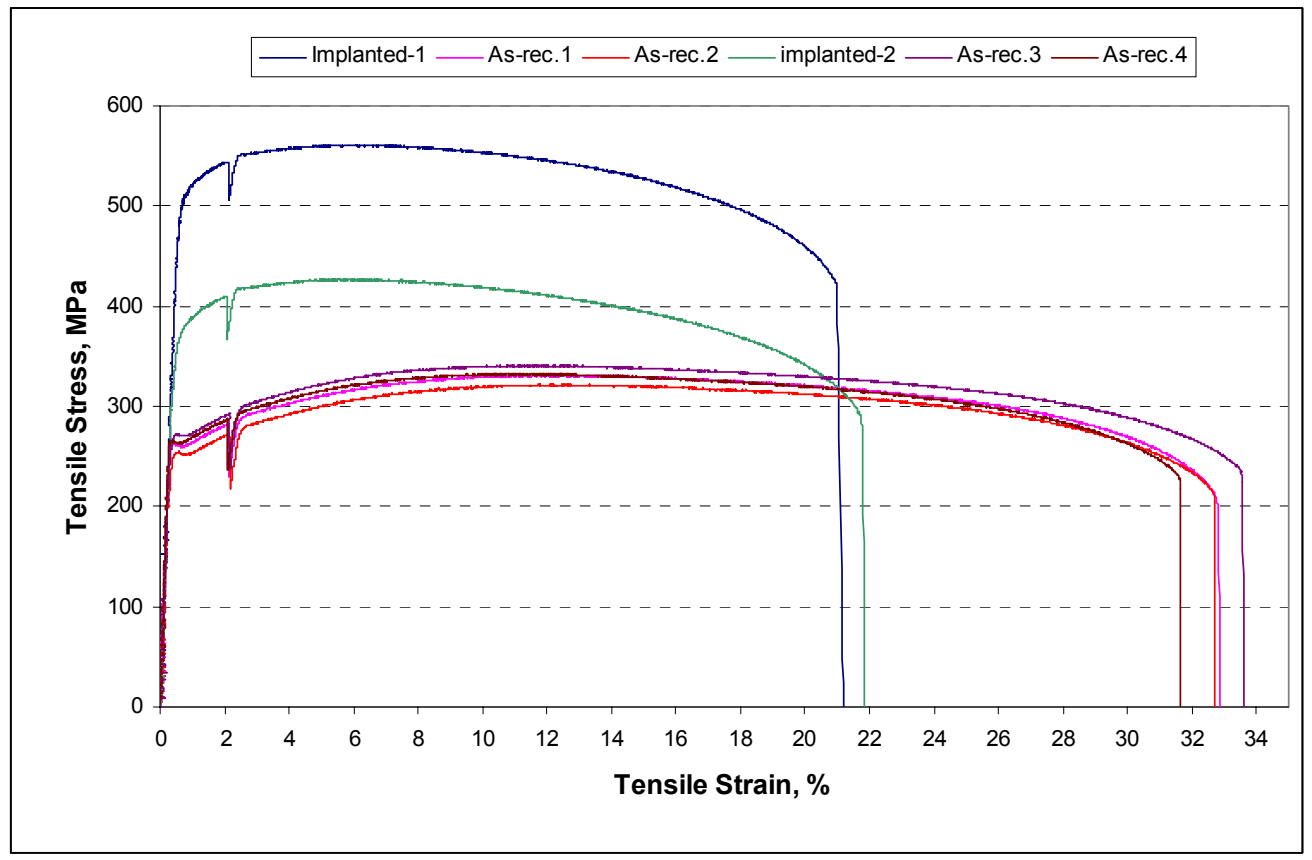

Fig. 19. Stress-strain curve of Zr-4 substrate with and without implantation.
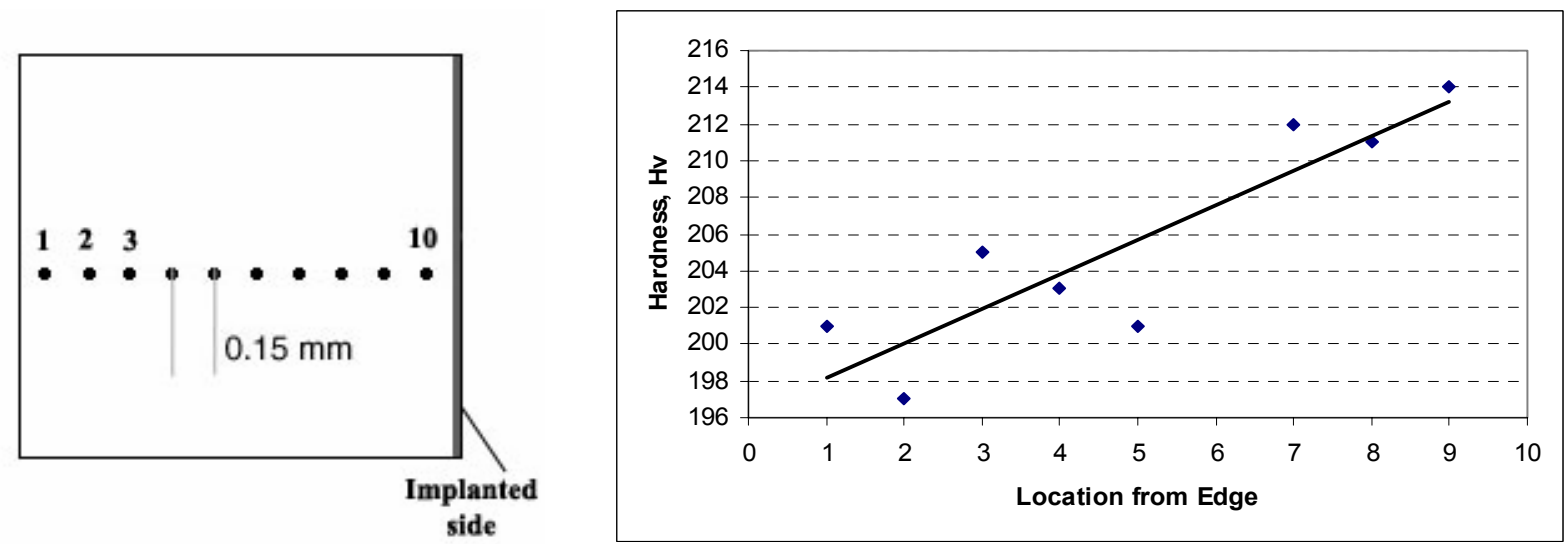

Fig 20. Vickers micro indentation profile made to the cross section of the implanted Zr-4 specimen. 


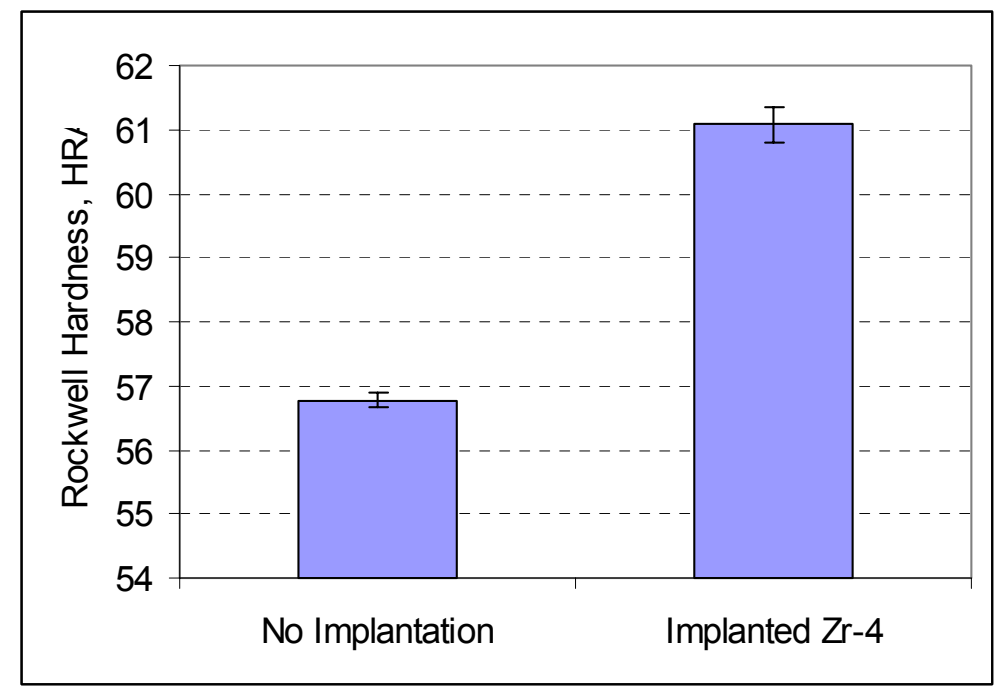

Fig. 21. Rockwell (HRA 60kg) hardness of Zirc-4 dog bones specimens with and without hydrocarbon implantation.

\section{Non chlorine-containing SiC Failure mechanism in autoclave}

Several models and mechanisms of SiC film failure in autoclave at $350^{\circ} \mathrm{C}$ and 3000 psi pressure for 24 hours were studied and analyzed including oxidation through pin holes which may involve normal and tangential stresses that causes delaminating of the film, formation and dissolution of $\mathrm{SiO}_{2}$ in high temperature water, and thermal stresses generated due to heating and cooling in the autoclave which may causes film cracking and failure due to thermal expansion mismatch. All theses mechanisms were analyzed by different means and they seem to be not valid.

The EDX mapping and line scan analysis, Fig. 22. and Fig. 23. have shown higher oxygen content in the film than in the holes and the bare metal in the fully detached areas. Based on these results and on the morphology of the crack and delaminating at early stages, another failure mechanism was tested, in which transformation from $\mathrm{SiC}$ to $\mathrm{SiO}_{2}$ occurs through the following reaction(s);

$\mathrm{SiC}+2 \mathrm{H}_{2} \mathrm{O}=\mathrm{SiO}_{2}+2 \mathrm{H}_{2}$

$\mathrm{SiC}+4 \mathrm{H}_{2} \mathrm{O}=\mathrm{SiO}_{2}+\mathrm{CO} 2+4 \mathrm{H}_{2}$

This transformation is accompanied with increase in volume, which induces compression residual stresses that may lead to buckling of the film as shown in Figure 23. Separations develop at the film/substrate interface as a result of tensions normal to the interface. Theses separations start and develop preferentially parallel to the scratch lines as shown in Figure 25 (a). 
Most of these buckles have an elliptical shape and they propagate until they join an adjacent buckle region as shown in Fig. 25(b). Spallation of the film forms in some of the large buckles particularly those that contain previously cracks as shown in Fig. 26(c).

It was reported in previous published studies that the compressed films delaminate only if the film buckles. Compression stresses were found in oxidation layers formed by inward diffusion of oxygen. Additional residual stresses may be formed by vapor deposition during cooling because of the thermal expansion mismatch between ceramic film and metal substrate.

More analysis and calculation of stresses responsible for the film buckling and spallation will be carried out under a separate study. See figure 24 for a cartoon of the failure mode. Also the reason for preferential buckling along scratch lines (see figure 25) is not well understood and will be subject to more analysis.
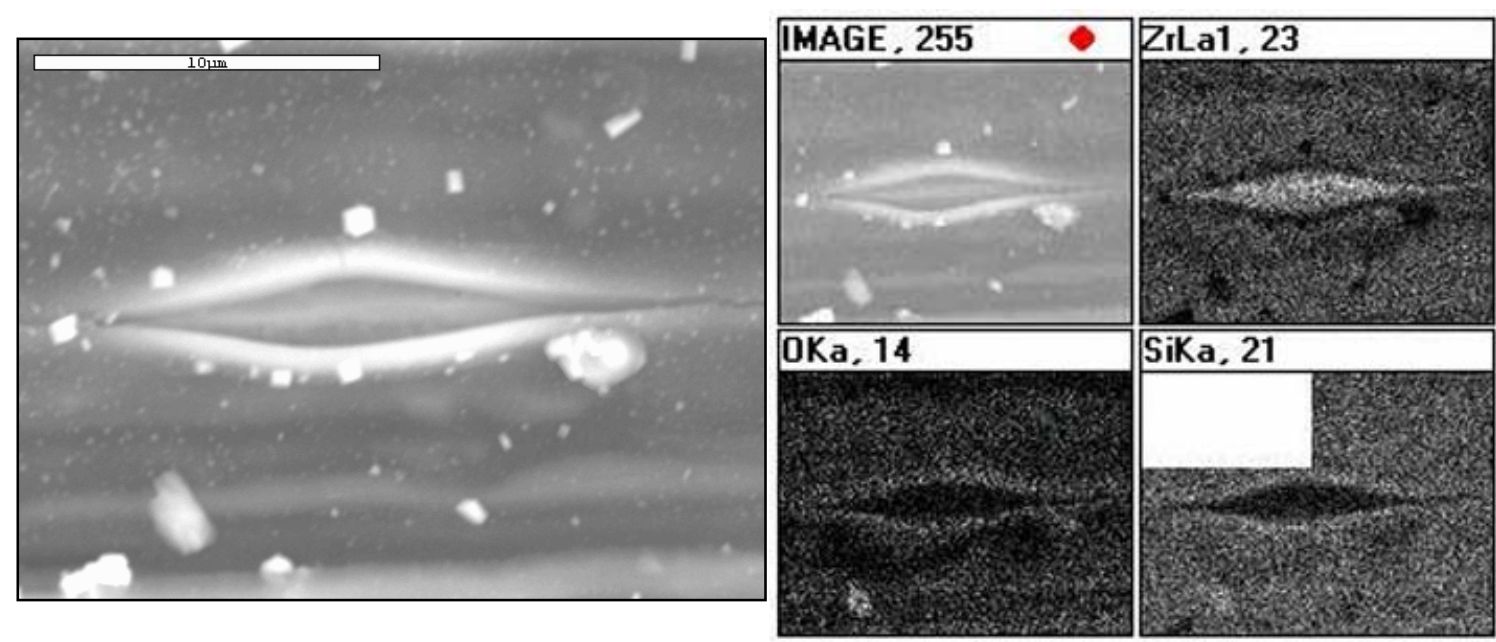

Fig. 22. SEM and EDX map shows the oxygen distribution in the areas where failure begins. 

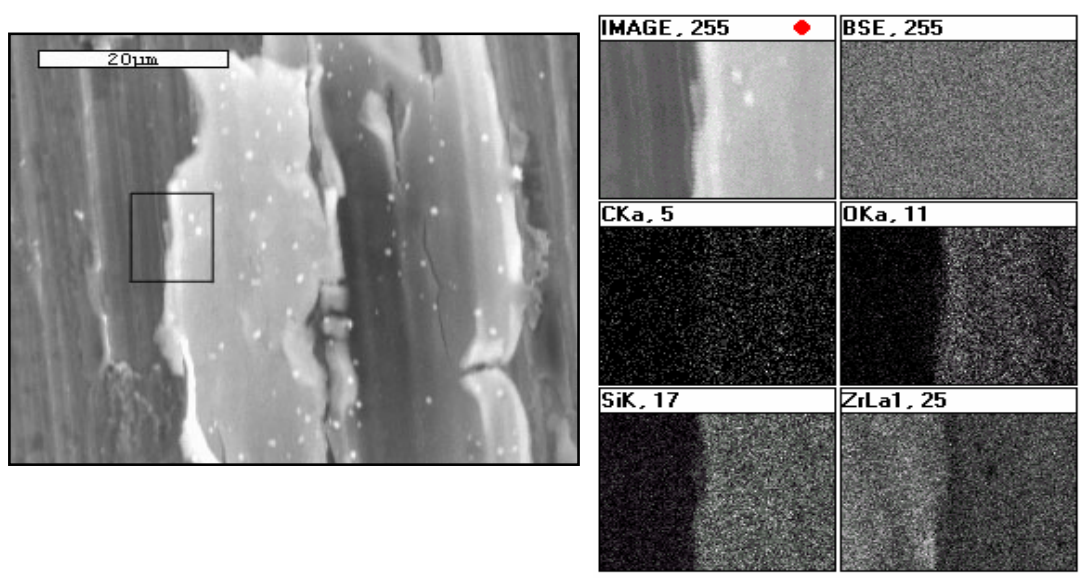

A

B
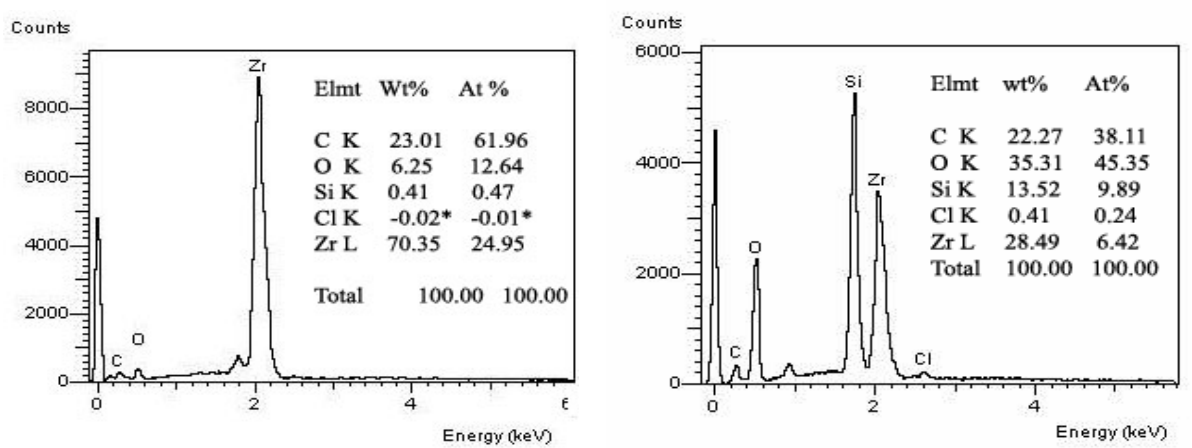

Fig. 23 Line scan and quantitative EDX analysis of partially failed film after autoclave test shows higher oxygen contents on the SiC film than on bare Zirc-4 metal.

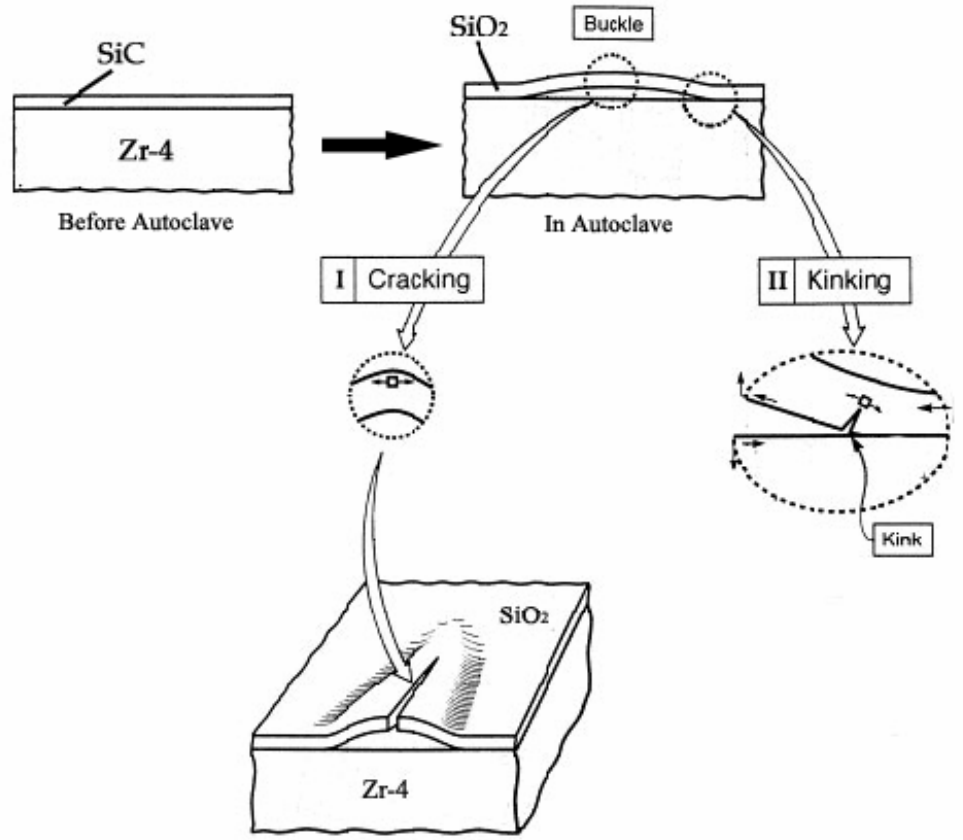

Fig.24. A schematic indicating the cracking and spalling phenomena that occur after buckling. 

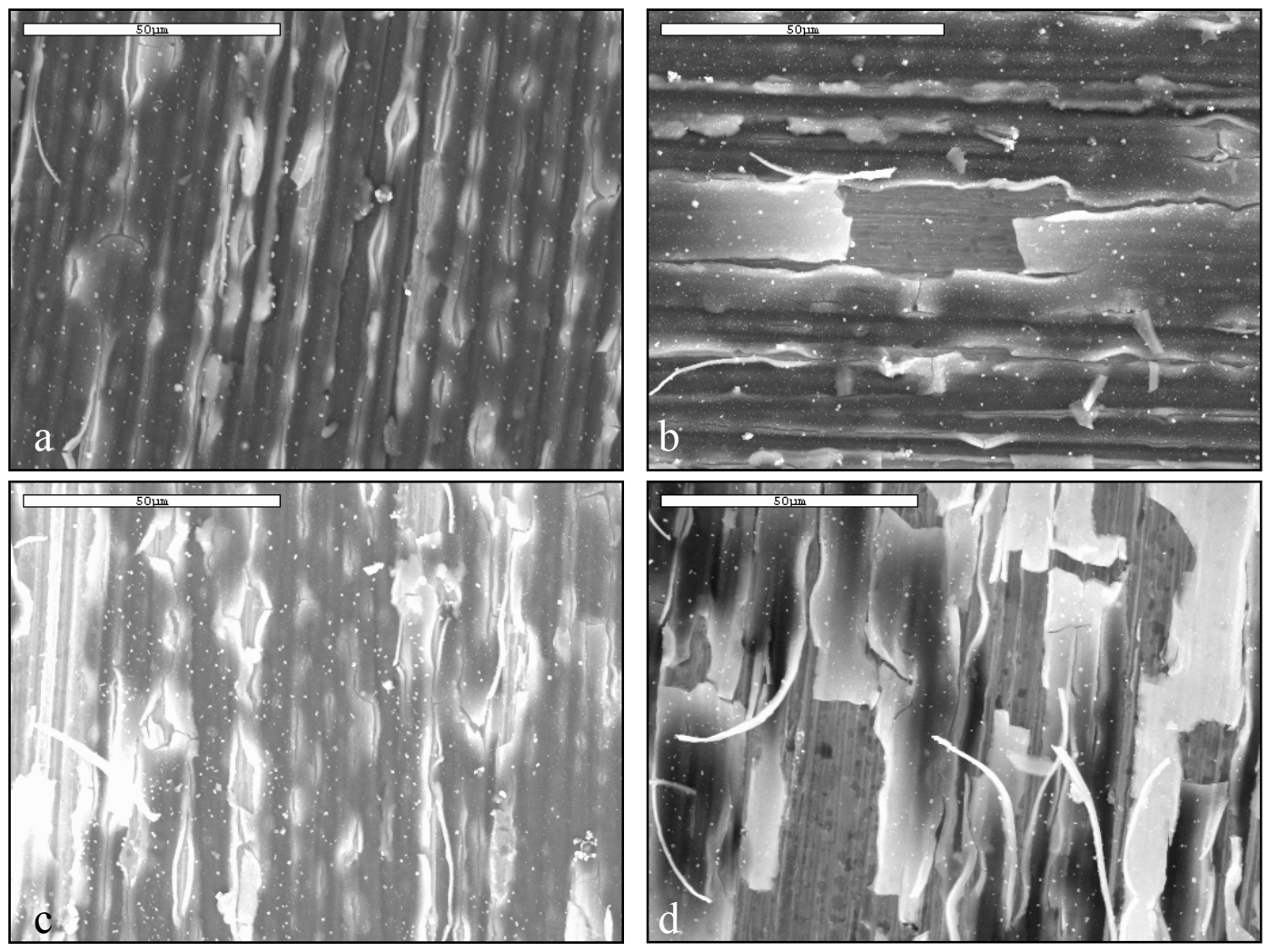

Fig. 25. SEM images shows; (a) cracks and buckles parallel to the scratch lines, (b) connection of adjacent buckles which lead to (c and d) spallation of the film.

Our observations on the hydrolytic oxidation of the SiC coatings is in contrast to studies of CVD formed $\mathrm{SiC}$ under similar hydrothermal conditions ${ }^{1}$ but is consistent for $\mathrm{SiC}$ under super critical water conditions. $^{2}$

\footnotetext{
${ }^{1}$ W. J. Kim, H.S.Hwang, and J.Y. Park, "Corrosion behavior of reaction bonded dilicon carbideceramics in hightemperature water", J. Mat. Sci. Letters, 21,(2002) 733.

${ }^{2}$ T. Kraft, K. G. Nickel,and Y. G. Gogotsi, "Hydrothermal degradation of chemical vapor deposited SiC fibers", J. Mat. Sci., 33 (1998) 4357.
} 


\section{Alumina coatings deposited by radio-frequency (RF) sputtering and by surface alloying with aluminum metal followed by oxidation}

\section{Introduction}

During the course of this NERI program several processes have been explored for coating Zirc-4 substrates with alumina. These included physical vapor deposition which produced too thick coatings and, UVCVD and sol-gel processing which produced very weak coating which were unstable in the autoclave environments of our screening tests,

Coating processes, which gave more robust alumina films, were examined in the last year and a half of the effort. One of those processing approaches was radio frequency (RF) sputtering using an alumina target. This method was employed to deposit stoichiometric alumina films onto Zircaloy-4 substrates. The stability of the films at simulated reactor conditions was determined by characterizing samples after autoclave exposure. Scanning electron microscopy (SEM), energy dispersive x-ray spectroscopy (EDX), and optical profilometry were used to investigate the surface morphology and composition of the films.

Surface alloying with aluminum onto the Zirc-4 substrates formed intermetalics such as $\mathrm{Al}_{3} \mathrm{Zr}$ and $\mathrm{Al}_{2} \mathrm{Zr}_{3}$ as determined by glancing angle $\mathrm{x}$-ray diffraction. These were oxidized to form $\mathrm{Al}_{2} \mathrm{O}_{3}$ and $\mathrm{ZrO}_{2}$ mixed phases upon oxidation.

\section{Experimental}

Zircaloy-4 substrates were polished using 600 grit SiC paper and $1 \mu \mathrm{m}$ alumina powder.

For surface alloying, aluminum metal films were deposited on the Zircaloy substrates using an electron beam evaporator. The deposited films thickness was $\sim 300 \mathrm{~nm}$. The aluminum films were oxidized in air using a tube furnace. Samples were oxidized using either an isothermal annealing at $500^{\circ} \mathrm{C}$ or a two-step heat treatment at $650{ }^{\circ} \mathrm{C}$ followed by at $500^{\circ} \mathrm{C}$. After heat treatment, samples were cooled to room temperature in the furnace.

The operating condition of the sputter system used to form the stoichiometric alumina films employed a base pressure of 1x10-5 Torr and an operating pressure of $\sim 5 \times 10-3$ Torr. Argon flow was maintained at $5 \mathrm{sccm}$ and the RF power was held at $100 \mathrm{~W}$. Coatings were deposited at room temperature for 5 hours with a target-substrate distance of 2 inches in order to obtain a coating thickness of $\sim 1 \mu \mathrm{m}$.

The coated samples were placed in an autoclave to assess coating durability at simulated reactor conditions. Autoclave tests were performed at $350^{\circ} \mathrm{C}$ and 3000 psig for $24 \mathrm{~h}$. Crystal phases from selected samples were characterized by glancing angle x-ray diffraction (GAXRD). 


\section{Results and discussion for the $\mathrm{Al}_{2} \mathrm{O}_{3}$ sputter coated samples}

Figure 26 shows the SEM micrographs of a $1 \mu \mathrm{m}$ alumina coating on Zircaloy-4 after autoclave exposure (substrate polished with 600 grit $\mathrm{SiC}$ paper). The deposited coating was partially destroyed exposing the underlying substrate. The result shows that the coating had poor adhesion to the substrate.

An alumina film deposited on Zircaloy (600 grit polish) was annealed after deposition at $450^{\circ} \mathrm{C}$ for 2 hours. Figure 27 shows the surface of this sample after autoclave exposure. Film delamination was not observed as in Figure 26. However, the surface is covered with faceted particles roughly $0.1-0.5 \mu \mathrm{m}$ in diameter. In addition, there are particle clusters that are typically several microns in diameter randomly distributed on the surface.

EDX compositional data (Table 2) indicates that the particles are oxides of aluminum, and GAXRD discussed below indicate that the crystals are boehmite, AlOOH.
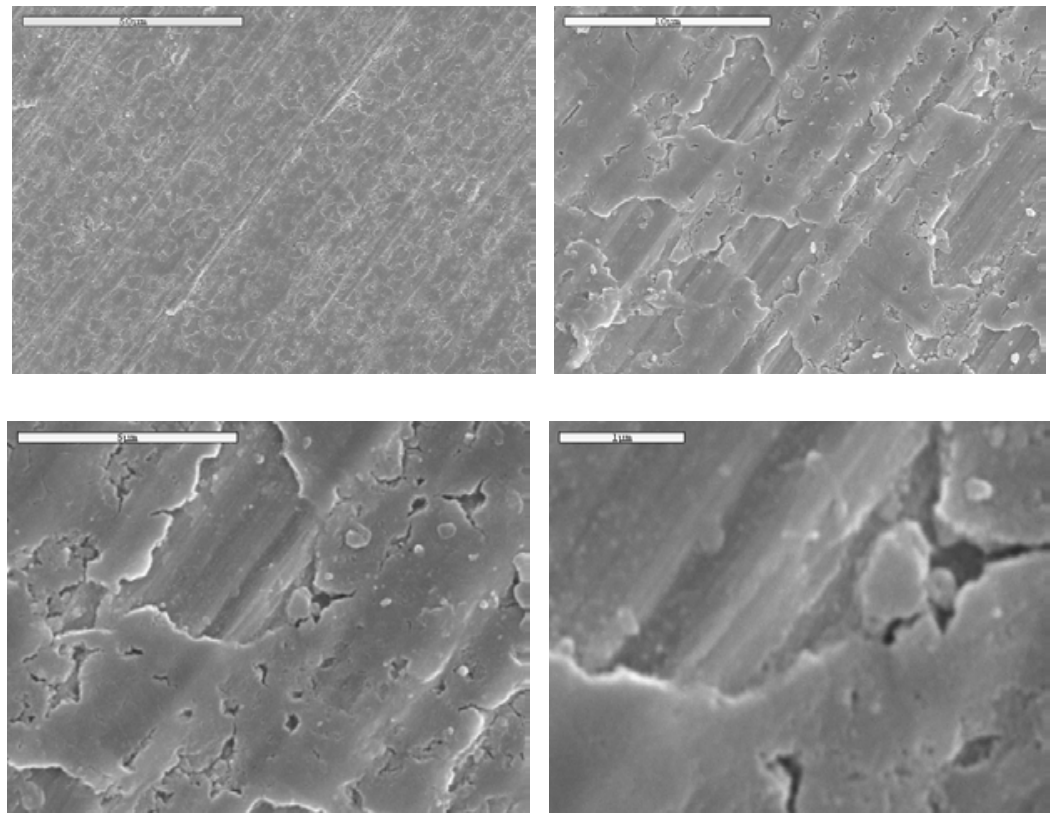

Figure 26. SEM micrographs of a sputter deposited alumina film on Zircaloy after autoclave exposure for 24 hours. 

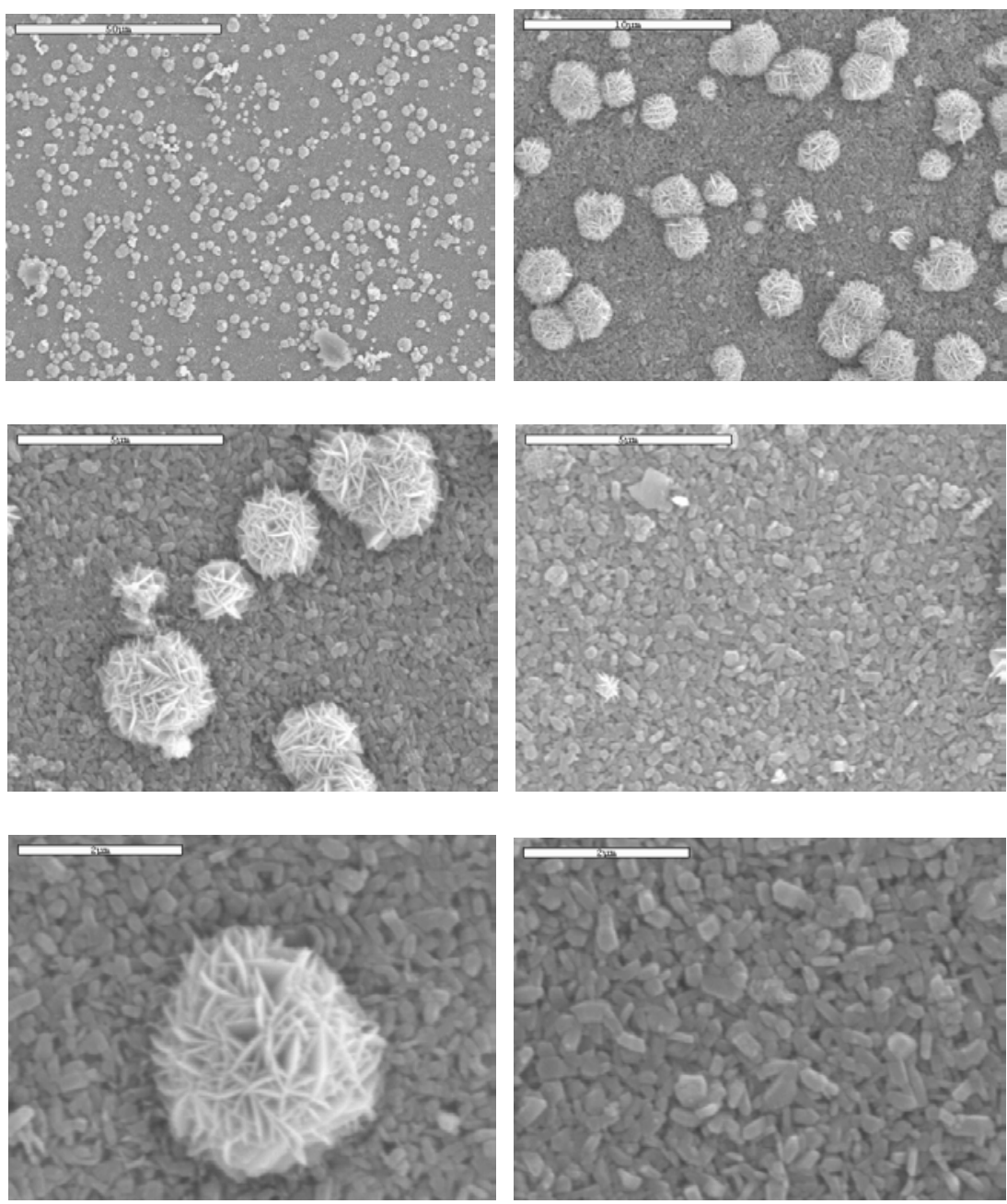

Figure 27. SEM micrographs of a sputter deposited alumina film on Zircaloy after autoclave exposure for 24 hours. The alumina film was annealed at $450^{\circ} \mathrm{C}$ for 2 hour after deposition.

\begin{tabular}{|c|c|c|c|c|c|}
\hline \multicolumn{3}{|c|}{ Background area } & \multicolumn{3}{|c|}{ Particle clusters } \\
\hline Element & $\begin{array}{l}\text { Spect. } \\
\text { type }\end{array}$ & $\begin{array}{c}\text { Atomic } \\
\%\end{array}$ & Element & $\begin{array}{c}\text { Spect. } \\
\text { type }\end{array}$ & $\begin{array}{c}\text { Atomic } \\
\%\end{array}$ \\
\hline $\mathrm{O} \mathrm{K}$ & ED & 73.54 & $\mathrm{OK}$ & ED & 68.14 \\
\hline $\mathrm{Al} \mathrm{K}$ & ED & 13.69 & Al K & ED & 8.68 \\
\hline \multirow[t]{3}{*}{ Zr L } & ED & 12.77 & $\mathrm{Fe} \mathrm{K}$ & ED & 5.06 \\
\hline & & & $\mathrm{Zr} \mathrm{L}$ & ED & 2.13 \\
\hline & & & Mo L & ED & 15.99 \\
\hline \multicolumn{2}{|c|}{ Total } & 100.00 & \multicolumn{2}{|c|}{ Total } & 100.00 \\
\hline
\end{tabular}

Table 3. EDX compositional analysis of the alumina film after annealing at $450^{\circ} \mathrm{C}$ for $2 \mathrm{hr}$. 
Figure 28 shows SEM micrographs of alumina coated Zircaloy substrates after autoclave exposure for 24 hours. The alumina films were formed by sputter depositing and then annealing at $550^{\circ} \mathrm{C}$ for 2 hours. After increasing the annealing temperature to $550^{\circ} \mathrm{C}$ and with the same values of the other process parameters, well-faceted particles on the sample surfaces were observed with a particle size of about $0.1-0.5 \mu \mathrm{m}$. A small amount of strange shape islands with a few flakes were also observed on the surfaces.

EDX compositional analysis (Table 4) of the sample surfaces showed a larger amount of aluminum than in the sample annealed on $450^{\circ} \mathrm{C}$ (Table 3). This may be an indication of a thicker particle layer.
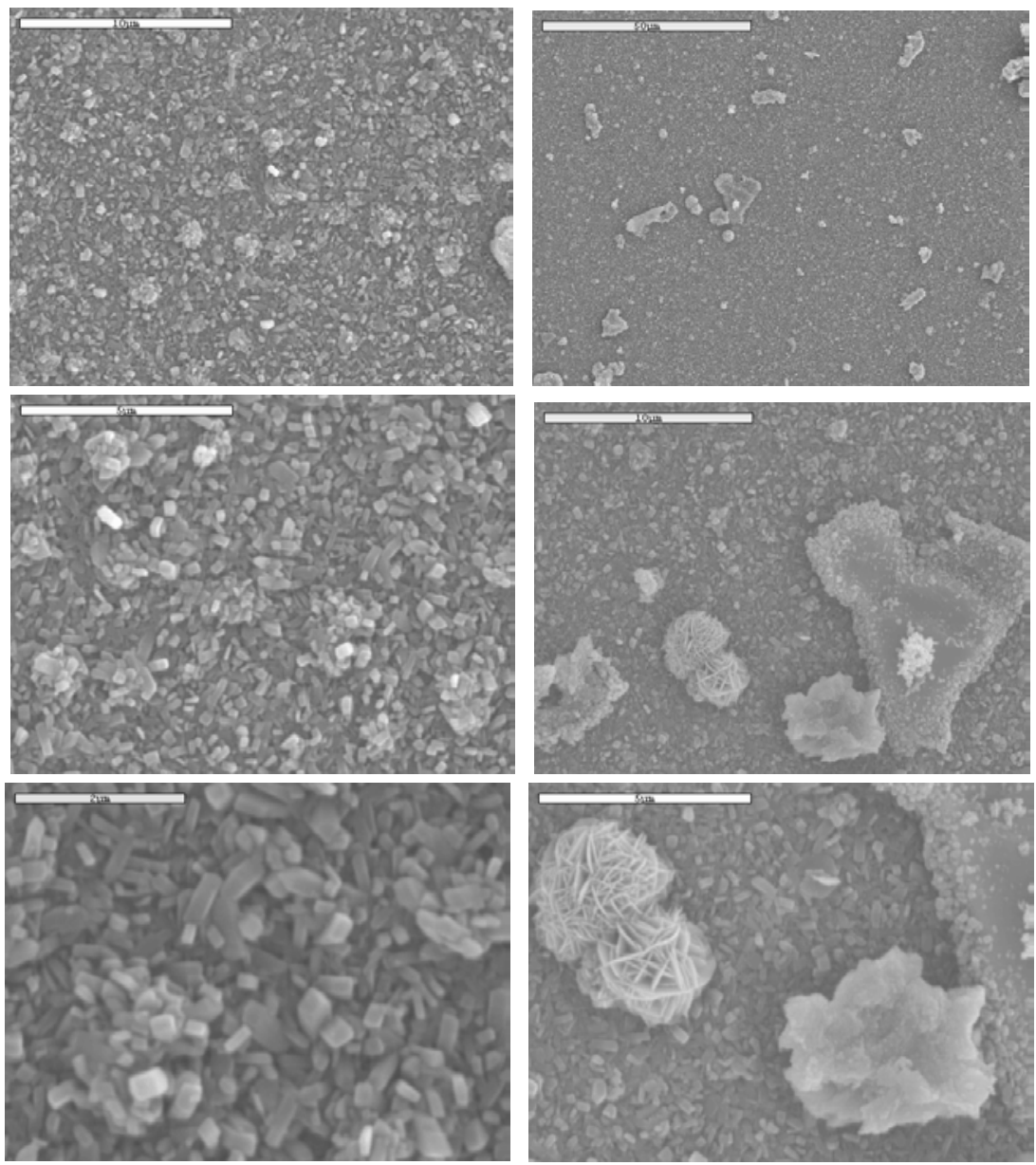

Figure 28. SEM micrographs of a sputter deposited alumina film on Zircaloy after autoclave exposure for 24 hours. The alumina film was annealed at $550^{\circ} \mathrm{C}$ for 2 hours. 


\begin{tabular}{|c|c|c|c|c|c|}
\hline \multicolumn{3}{|c|}{ Background area } & \multicolumn{3}{|c|}{ Particle clusters } \\
\hline Element & $\begin{array}{c}\text { Spect. } \\
\text { type }\end{array}$ & $\begin{array}{c}\text { Atomic } \\
\%\end{array}$ & Element & $\begin{array}{c}\text { Spect. } \\
\text { type }\end{array}$ & $\begin{array}{c}\text { Atomic } \\
\%\end{array}$ \\
\hline $\mathrm{OK}$ & $\mathrm{ED}$ & 72.58 & $\mathrm{OK}$ & ED & 78.52 \\
\hline $\mathrm{Al} \mathrm{K}$ & ED & 22.67 & $\mathrm{Al} \mathrm{K}$ & ED & 21.48 \\
\hline Zr L & ED & 4.74 & & & \\
\hline \multicolumn{2}{|c|}{ Tot: } & 100.00 & To & & 100.00 \\
\hline
\end{tabular}

Table 4. EDX compositional analysis of a sputter deposited alumina film after annealing at $550^{\circ} \mathrm{C}$ for 2 hours.

Figure 29 shows the surface of an alumina coating that was annealed at $650^{\circ} \mathrm{C}$ for 2 hours and placed in the autoclave for 24 hours. There are regions on this sample in which the upper layer of particles has delaminated, revealing gaps in the particle layers as well as flakes of the coating deposited on the sample surface.

The elemental composition of this sample (Table 5) was similar to that of the sample annealed at $550^{\circ} \mathrm{C}$. The exposed areas are not the Zircaloy-4 substrate, as their composition is almost identical to the surface particle layer.

The surface roughness of the samples varied depending on the annealing temperature, with the sample annealed at $550^{\circ} \mathrm{C}$ having the highest value (Figure 30). 

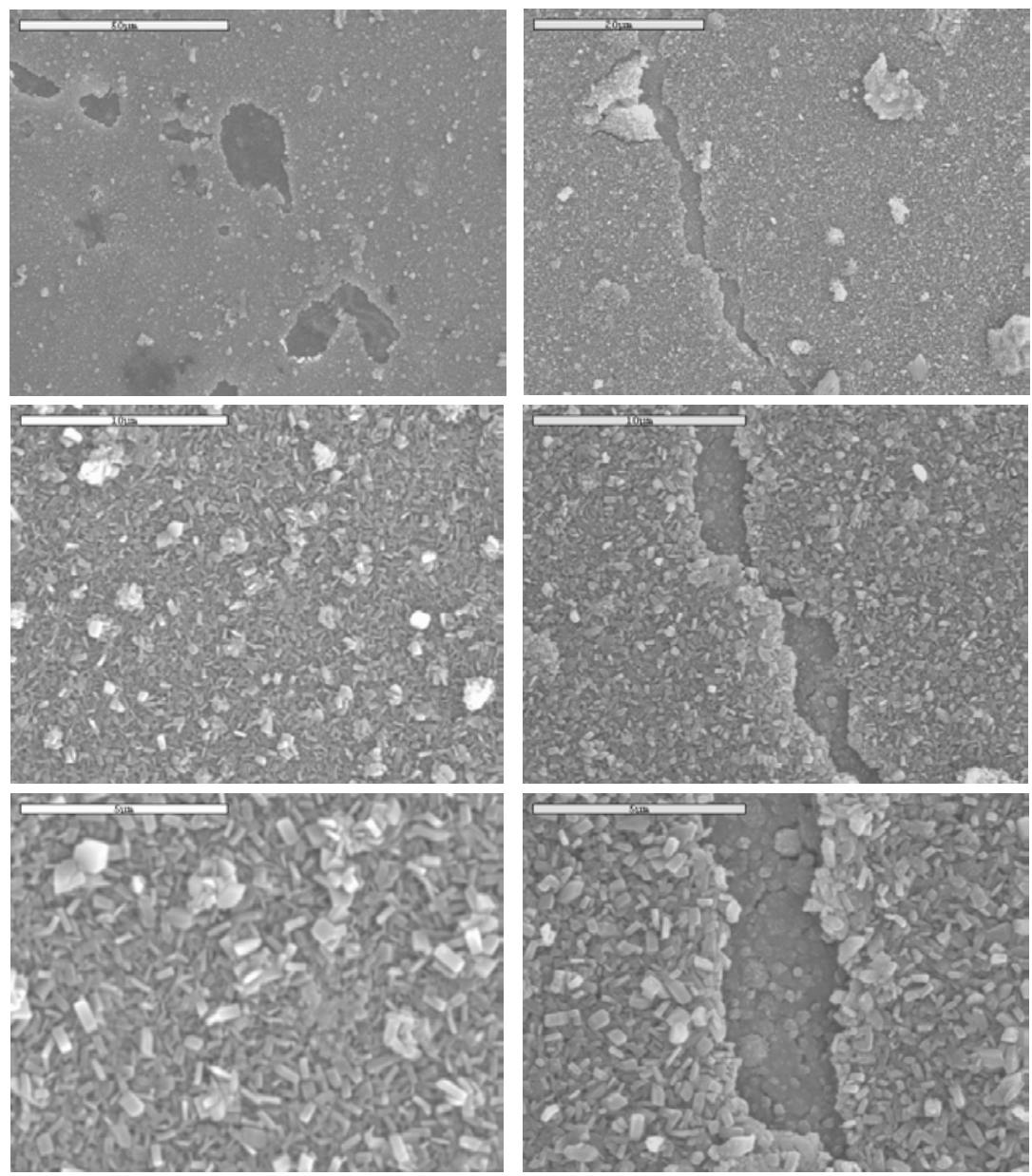

Figure 29. SEM micrographs of a sputter deposited alumina film on Zircaloy after autoclave exposure for 24 hours. The alumina films was deposited and annealed at $650^{\circ} \mathrm{C}$ for $2 \mathrm{hr}$.

\begin{tabular}{|lcc|lcc|}
\hline \multicolumn{3}{|c|}{ Exposed under layer } & \multicolumn{3}{c|}{ Upper surface } \\
Element & $\begin{array}{c}\text { Spect. } \\
\text { type }\end{array}$ & $\begin{array}{c}\text { Atomic } \\
\%\end{array}$ & Element & $\begin{array}{c}\text { Spect. } \\
\text { type }\end{array}$ & $\begin{array}{c}\text { Atomic } \\
\%\end{array}$ \\
\hline O K & ED & 67.20 & O K & ED & 71.58 \\
Al K & ED & 20.21 & Al K & ED & 22.93 \\
Zr L & ED & 12.59 & Zr L & ED & 5.49 \\
\hline \multicolumn{2}{|c|}{ Total } & 100.00 & \multicolumn{2}{|c|}{ Total } & 100.00 \\
\hline
\end{tabular}

Table 5. EDX compositional analysis of the alumina film after annealed at $650^{\circ} \mathrm{C}$ for $2 \mathrm{hr}$ 


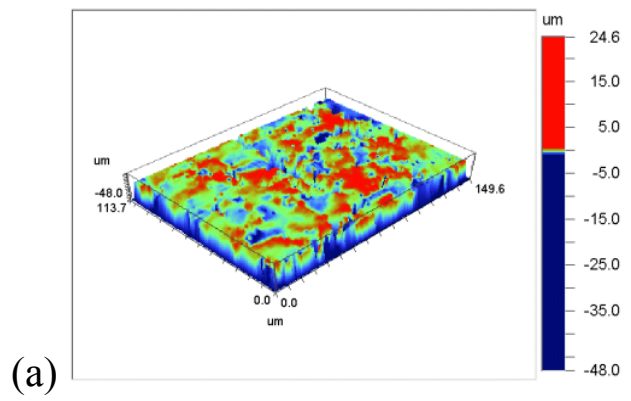

(b)

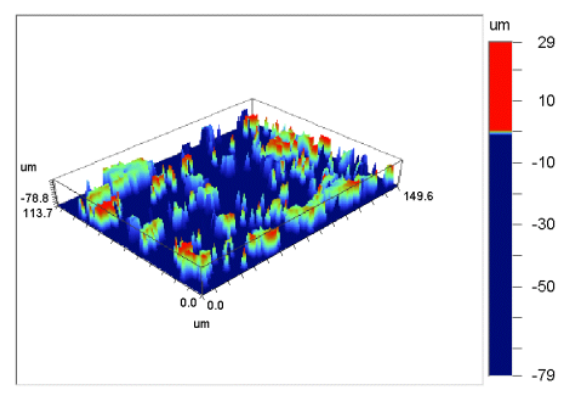

(c)

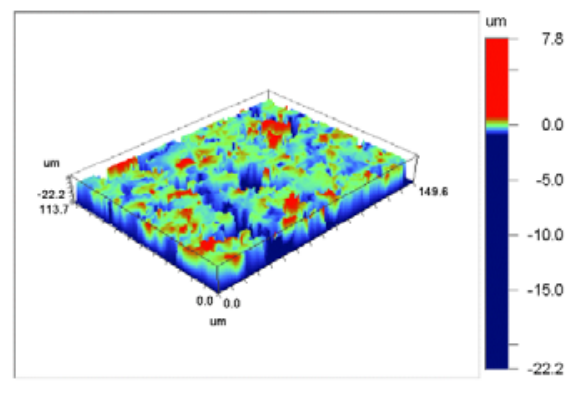

Fig. 30. Optical profilometer images of a sputter deposited alumina film on Zircaloy after autoclave exposure for 24 hours. The alumina films were deposited and annealed for $2 \mathrm{hr}$ at (a) $450^{\circ} \mathrm{C}$, (b) $550^{\circ} \mathrm{C}$ and (c) $650^{\circ} \mathrm{C}$, respectively

Glancing angle x-ray diffraction (GAXRD) results revealed the unknown phase of the hydrothermally grown crystallites. Figure 31 shows the normal XRD (a) and GAXRD (b) results for a sputter deposited alumina film on Zircaloy after autoclave exposure for 24 hours. The normal powder XRD peaks showed some zirconium peaks and a couple of aluminum hydroxide peaks (maybe boehmite). However, in the GAXRD peaks, the boehmite peaks greatly increased. Moreover, several other peaks appeared which were consistent with boehmite and zirconia. This suggests the boehmite and zirconia crystallites were formed hydrothermally on the surface region of the samples during the autoclave exposure.

Hydrothermal formation of $\mathrm{AlOOH}$ was unexpected. Under similar conditions monolithic pieces of $\mathrm{Al}_{2} \mathrm{O}_{3}$ resisted corrosion ${ }^{3}$ Dissolution of grain boundary impurities was the only observed form of corrosion? Since the sputtered alumina coating should not contain significant amounts of grain boundary impurities hydrothermal dissolution and re-precipitation of boehmite was not expected.

\footnotetext{
${ }^{3}$ K. Oda, and T. Yoshio, "Hydrothermal corrosion of alumina ceramics", J. Am. Cer. Soc.80 (1997) 3233.
} 


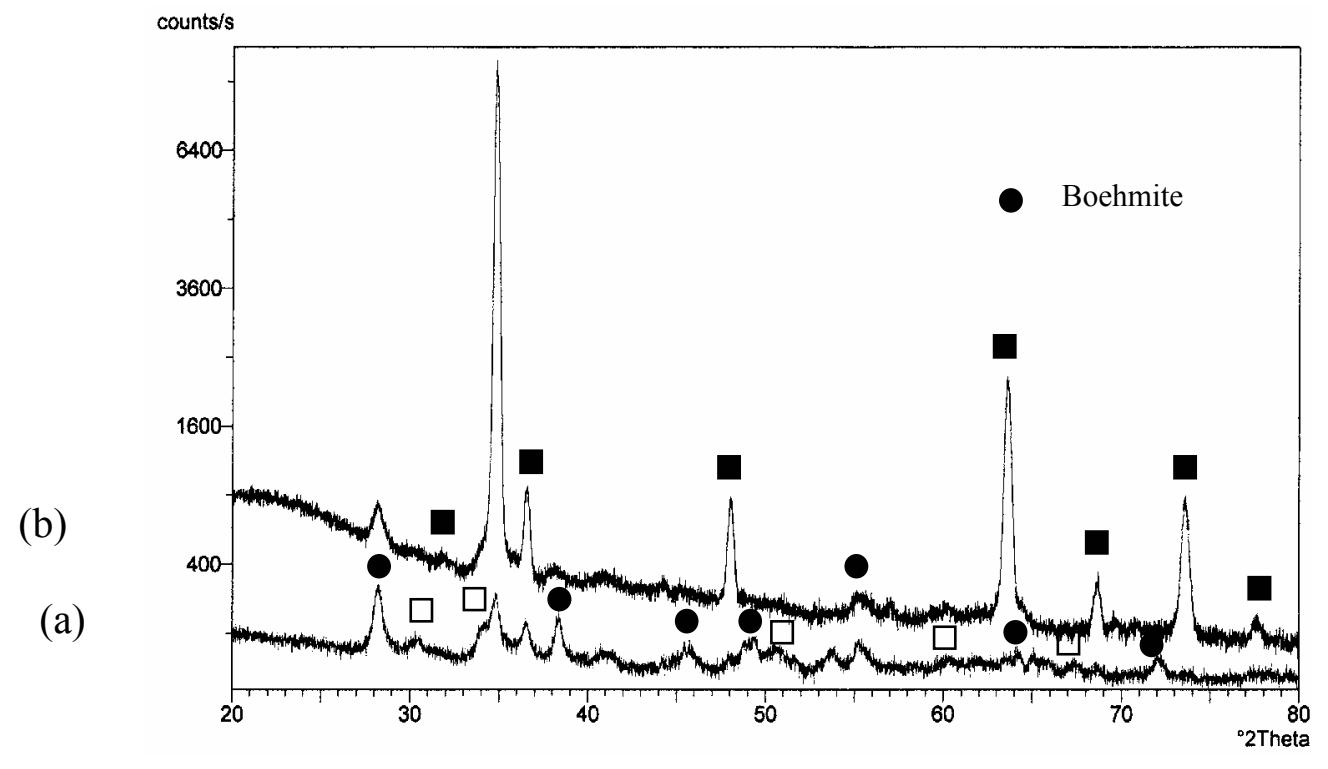

Figure 31. (a) Glancing angle x-ray diffraction (GAXRD) and (b) normal XRD spectra for a sputter deposited alumina film on Zircaloy after autoclave exposure for 24 hours. The alumina film was annealed at $550^{\circ} \mathrm{C}$ before autoclave exposure.

\section{Electrochemical corrosion tests in $1000 \mathrm{ppm}$ boric acid solution of alumina coated Zirc-4 formed by surface alloying with aluminum followed by oxidation}

\section{Overview}

Aluminum coatings were deposited on Zircaloy-4 (Zirc-4) substrates by electron beam evaporation and oxidized at various conditions to obtain alumina coatings. To investigate the corrosion properties of the coatings, electrochemical impedance and potentiodynamic measurements were conducted in 1,000 ppm boric acid solution.

\section{Experiments}

The preparation of substrates and alumina coatings was discussed in the previous report (Year 3, Quarter 3 progress report). Coatings were prepared by the controlled oxidation of aluminum thin films deposited by electron beam evaporation onto Zircaloy-4 substrates. To investigate the electrochemical behavior of the coatings, DC potentiodynamic and electrochemical impedance measurements (EIS) were conducted in 1,000 ppm boric acid solution at room temperature. Boric acid is used to decrease the solution resistance without destroying the coated samples. Solutions are purged with ultra high-purity Ar gas for 2 hours prior to the electrochemical tests. The solution $\mathrm{pH}$ was 5.9. Two high-purity graphite rods were used as counter-electrodes and the reference electrode was a saturated calomel electrode (SCE; 0.241 vs. SHE). The electrochemical measurements were made using an EG\&G Princeton Applied Research (Princeton, New Jersey, USA) electrochemical cell and a GAMRY PC4 potentiostat and connected frequency analyzer. The electrochemical potentiodynamic tests were performed at 1 
$\mathrm{mV} / \mathrm{s}$ from -0.2 to +0.2 with respect to the corrosion potential $\mathrm{E}_{\text {corr. }}$ Impedance spectra were measured over a wide frequency range $(100,000-0.01 \mathrm{~Hz})$ with a $5 \mathrm{mV}$ AC excitation amplitude.

\section{Results}

DC potentiodynamic tests.

Potentiodynamic tests were conducted with a small range $(-0.2$ to +0.2$)$ against the open-circuit potential in order to prevent damage to the coatings. From theses curves, the corrosion potential, $\mathrm{E}_{\text {corr }}$, as well as corrosion current, $\mathrm{I}_{\text {corr }}$, was determined for the coated specimen. Using anodic and cathodic slopes, as well as the corrosion current, the corrosion resistance was also calculated. The potentiodynamic curves and calculated data are shown in Figure 32 and Table 6 . As seen in the potentiodynamic curves, alumina coated sample annealed at $500^{\circ} \mathrm{C}$ displays almost the same corrosion current comparing as the uncoated samples. This result indicates very poor corrosion protective properties of the annealed aluminum coating. However, an extremely small corrosion current and higher corrosion potential were observed for the step-annealed sample $\left(650-500^{\circ} \mathrm{C}\right)$. These results show that the annealing temperature affects on the electrochemical stability of the layer.

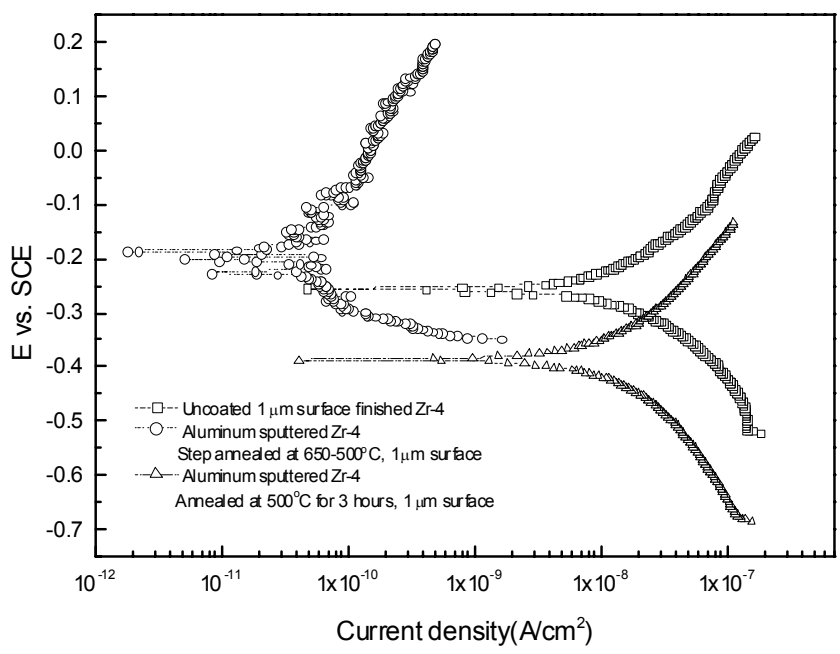

Figure 32. Potentiodynamic curves for alumina coated $\mathrm{Zr}-4$ in $1000 \mathrm{ppm}$ boric acid at $22^{\circ} \mathrm{C}(\mathrm{pH} 5.9)$. 


\begin{tabular}{cccc}
\hline Samples & $\begin{array}{c}\text { Current density } \\
\left(\mathbf{A} / \mathbf{c m}^{2}\right)\end{array}$ & $\begin{array}{c}\text { Corrosion potential } \\
(\mathbf{m V})\end{array}$ & $\begin{array}{c}\text { Corrosion resistance } \\
\left(\mathbf{\Omega} \mathbf{~ c m}^{\mathbf{2}}\right)\end{array}$ \\
\hline $\begin{array}{c}\text { Uncoated } \mathrm{Zr}-4 \\
(1 \mu \mathrm{m} \text { surface })\end{array}$ & $3.3 \times 10^{-8}$ & -251.4 & $2.5 \times 10^{6}$ \\
$\begin{array}{c}\text { Step annealed in air } \\
\left(650-500^{\circ} \mathrm{C}\right)\end{array}$ & $4.2 \times 10^{-11}$ & -187.9 & $1.6 \times 10^{9}$ \\
$\begin{array}{c}\text { Annealed in air at } \\
500^{\circ} \mathrm{C}\end{array}$ & $2.5 \times 10^{-8}$ & -384.5 & $3.4 \times 10^{6}$ \\
\hline
\end{tabular}

Table 6. Summary of DC potentiodynamic tests.

Electrochemical impedance tests

To investigate the corrosion behavior of the alumina coated $\mathrm{Zr}-4$, the following simplified equivalent circuit (Figure 32) is suggested. $\mathrm{C}_{\text {coating }}$ and $\mathrm{C}_{\mathrm{Zr}}$ are the interfacial corrosion resistance of the coating and substrate. $\mathrm{R}_{\text {coat }}$ and $\mathrm{R}_{\mathrm{zr}}$ similarly designate the interfacial corrosion resistance of the coating and substrate. Figure 15 displays the EIS response of the uncoated and alumina coated $\mathrm{Zr}-4$ in $1000 \mathrm{ppm}$ boric acid solution. As expected, EIS response exactly agreed with previous DC potentiodynamic tests. The step-annealed sample exhibits higher low-frequency interfacial impedance, $|\mathrm{Z}|$, and lower interfacial coating capacitance, $\mathrm{C}_{\text {coating, }}$, than either the uncoated or $500^{\circ} \mathrm{C}$ annealed samples. This result demonstrates the excellent corrosion preventive properties of the step-annealed sample in aqueous environments. The simulated EIS parameters of alumina coated Zr-4 samples are summarized in Table 7.

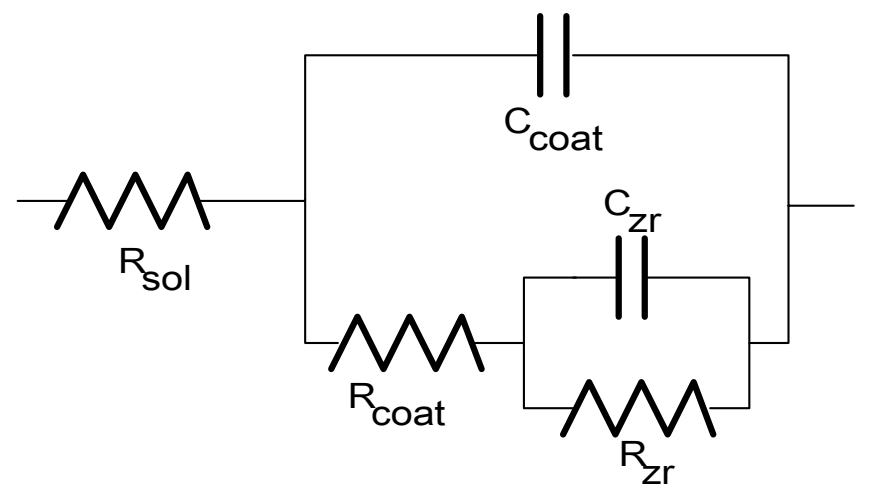

Figure 33. Equivalent circuit for the alumina deposited Zircaloy-4 

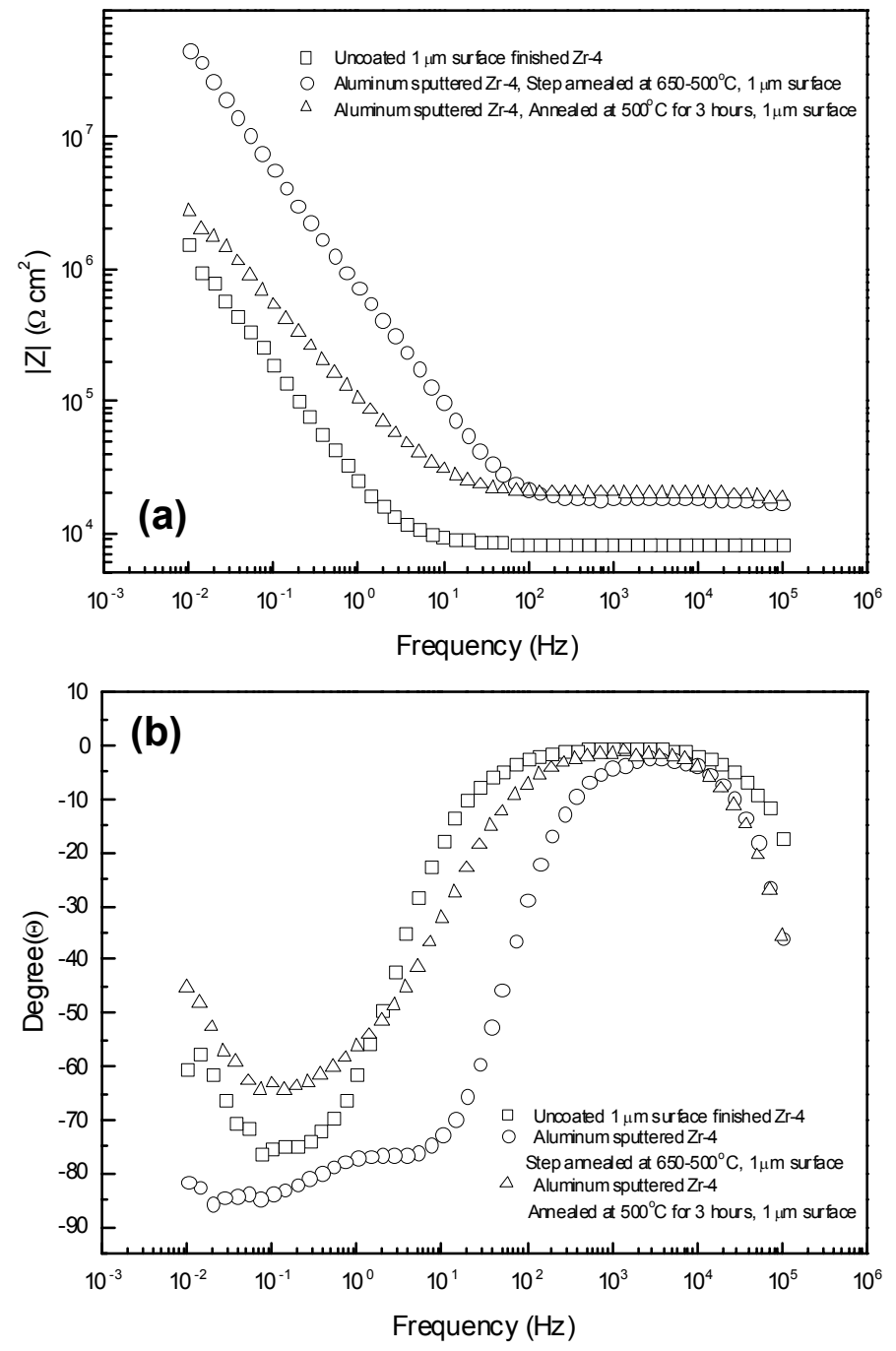

Figure 34. EIS spectra of the uncoated and alumina coated Zr-4 in $1000 \mathrm{ppm}$ boric acid solution. (a) Bode magnitude and (b) Bode phase plots.

\begin{tabular}{ccccc}
\hline Samples & $\mathbf{R}_{\text {azor }}\left(\mathbf{\Omega} \mathbf{~ c m}^{2}\right)$ & $\mathbf{C}_{\mathbf{Z r}}$ (Farads) & $\mathbf{R}_{\text {Coat }}\left(\mathbf{\Omega} \mathbf{~ c m}^{2}\right)$ & $\mathbf{C}_{\text {Coat }}($ Farads $)$ \\
\hline $\begin{array}{c}\text { Uncoated Zr-4 } \\
(\mathbf{1} \boldsymbol{\mu m} \text { surface })\end{array}$ & $1.8 \times 10^{6}$ & $8.3 \times 10^{-6}$ & - & - \\
$\begin{array}{c}\text { Step-annealed } \\
(\mathbf{6 5 0 - 5 0 0} \mathbf{C})\end{array}$ & $1.8 \times 10^{6}$ & $8.3 \times 10^{-6}$ & $2.2 \times 10^{8}$ & $2.5 \times 10^{-7}$ \\
Annealed at $\mathbf{5 0 0}^{\mathbf{0}} \mathbf{C}$ & $1.8 \times 10^{6}$ & $8.3 \times 10^{-6}$ & $5.7 \times 10^{5}$ & $2.3 \times 10^{-6}$ \\
\hline
\end{tabular}

Table 7. Calculated impedance parameters for the uncoated and alumina coated $\mathrm{Zr}-4$ by simulation of the equivalent circuit. 


\section{3-1. Aluminum oxide coatings by controlled oxidation of deposited aluminum metal films}

Figure.34 shows SEM micrographs of 300nm oxidized aluminum films after $24 \mathrm{~h}$ of autoclave exposure, which was shown in our last report. The Zircaloy substrates were polished with $1 \mu \mathrm{m}$ alumina powder prior to film deposition. Based on the presence of well-faceted particles on the sample surfaces, it was inferred that hydrothermal crystallization of aluminum oxide had occurred. The population density of the particulates was higher for the sample annealed using the two-step method (b).

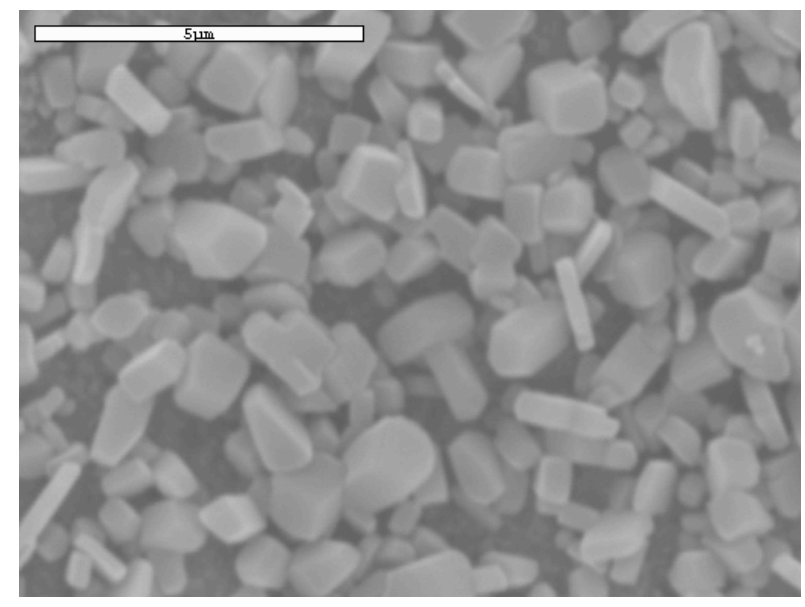

(a)

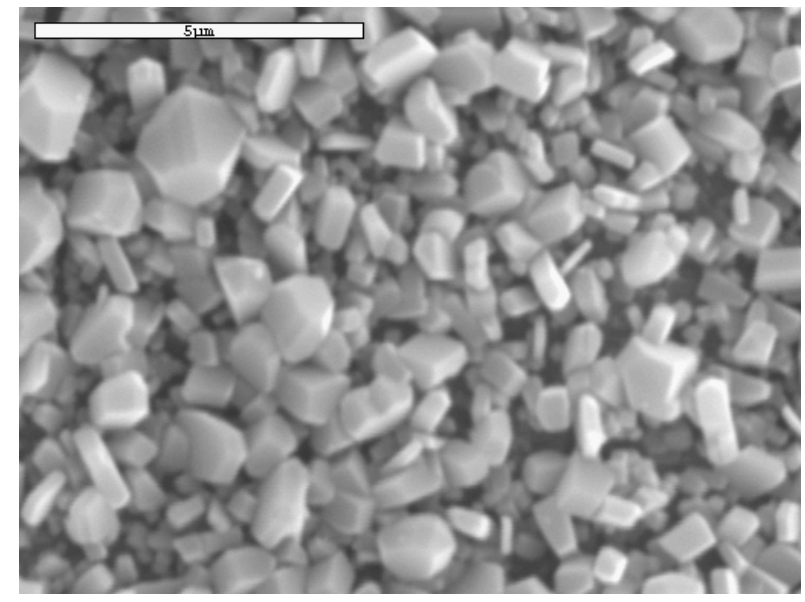

(b)

Figure 35 SEM micrographs of a 300nm oxidized aluminum film after autoclave exposure for 24 hours. The aluminum film was deposited on a Zircaloy substrate and oxidized (a) at $500{ }^{\circ} \mathrm{C}$ for $3 \mathrm{~h}$ and (b) at $650^{\circ} \mathrm{C}$ for $30 \mathrm{~min}$ followed by $500^{\circ} \mathrm{C}$ for $2 \mathrm{~h}$, respectively. The micrographs show what appear to be hydrothermally grown particles on the surface. 
In order to identify the phase of the crystallites and to confirm the morphology of the crystallites, transmission electron microscopy (TEM) was employed (Fig. 36). It was difficult to identify the phases in the diffraction patterns because more than one patterns appeared. This indicates that the crystallites patterns overlapped. Also, major patterns did not exactly match with the "jcpds" database. In the image photos, the well-faceted crystallites were clearly identified. In-situ energy dispersion x-ray spectroscopy (EDX) in Fig. 37 showed the elements of $\mathrm{Al}$ but without zirconium indicating that the crystallite should be aluminum oxide or hydroxide. The EDX instrument has limited sensitivity to light elements and so the presence of hydrogen cannot be determined. The presence of copper was due to sample holder.

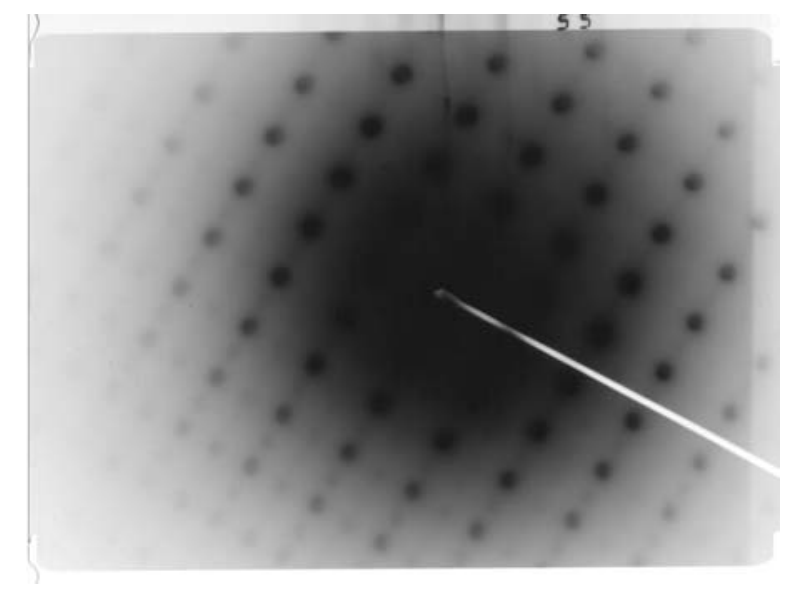

(a)

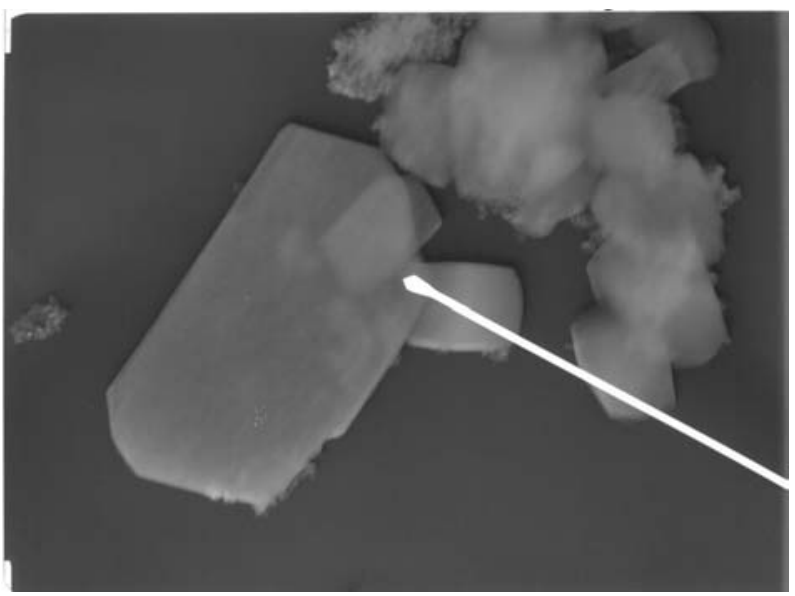

(b)

Figure 36 (a) TEM diffraction pattern and (b) TEM image of a 300nm oxidized aluminum film after autoclave exposure for 24 hours. The aluminum film was deposited on a Zircaloy substrate and oxidized at $650^{\circ} \mathrm{C}$ for $30 \mathrm{~min}$ followed by $500^{\circ} \mathrm{C}$ for $2 \mathrm{~h}$. 


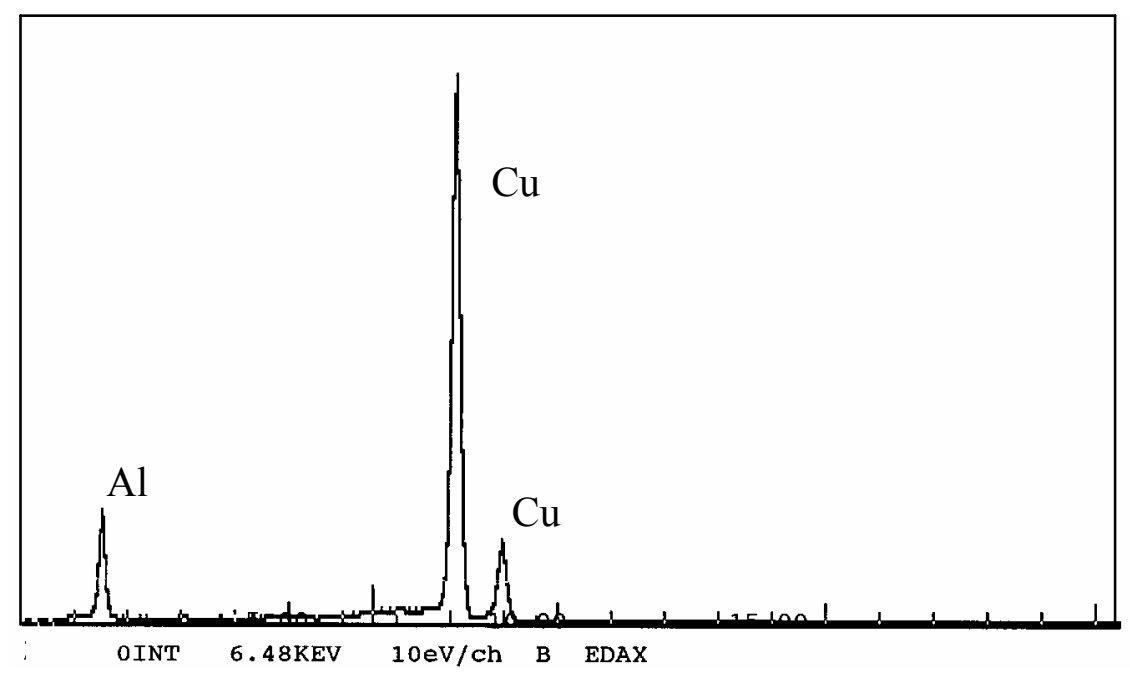

Figure 37: In-situ energy dispersion x-ray spectroscopy (EDX) in TEM of a 300nm oxidized aluminum film after autoclave exposure for 24 hours. The aluminum film was deposited on a Zircaloy substrate and oxidized at $650^{\circ} \mathrm{C}$ for $30 \mathrm{~min}$ followed by $500^{\circ} \mathrm{C}$ for $2 \mathrm{~h}$.

Glazing angle x-ray diffraction (GAXRD) was also used for phase identification of the hydrothermally grown crystallite, shown in Fig. 38. The GAXRD spectrum showed that the peaks of boehmite (black circles) and zirconia (black squares) were increased in height compared with normal XRD peaks. This effect was more obvious when the Y-axis was converted to a log scale. This evidence confirms that the surface was covered by boehmite and zirconia crystallites.

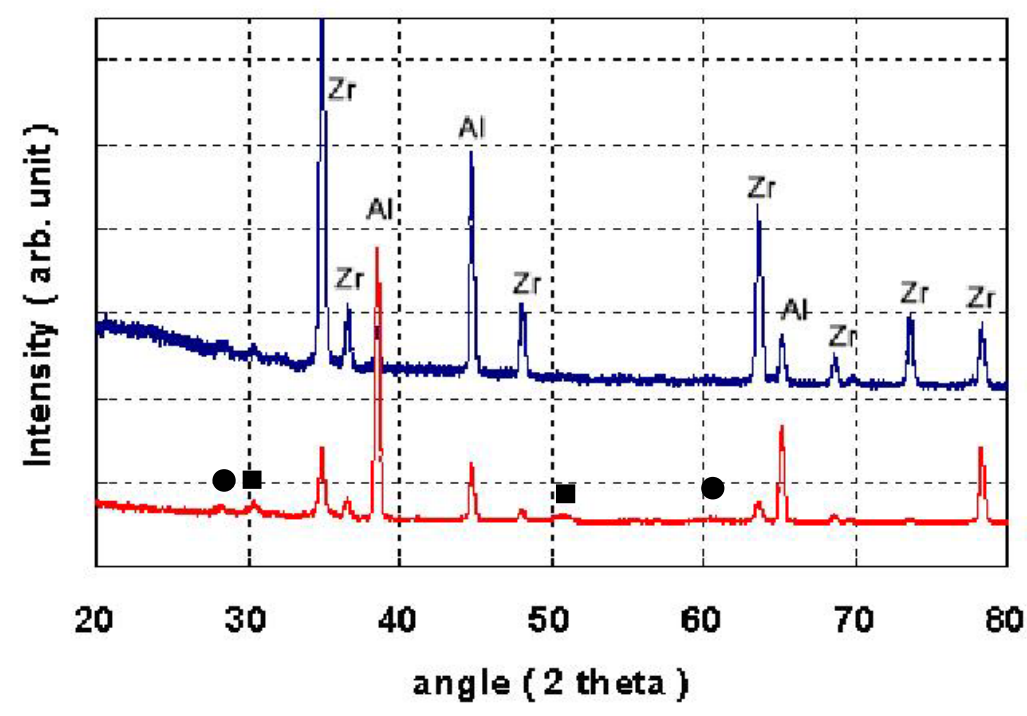

(a)

Figure 38: (a) powder XRD and (b) glazing angle x-ray diffraction spectra (GAXRD) of a $300 \mathrm{~nm}$ oxidized aluminum film after autoclave exposure for 24 hours. The aluminum film was deposited on a Zircaloy substrate and oxidized at $650^{\circ} \mathrm{C}$ for $30 \mathrm{~min}$ followed by $500^{\circ} \mathrm{C}$ for $2 \mathrm{~h}$. 


\section{3-2. Sputter deposited alumina coating}

Figure 39 shows SEM micrographs of alumina coated Zircaloy substrates after autoclave exposure for 24 hours (substrate polished with 600 grit $\mathrm{SiC}$ paper). The alumina films were sputter deposited and then annealed at $550^{\circ} \mathrm{C}$ and $650^{\circ} \mathrm{C}$ respectively, for 2 hours. Well-faceted particles on the sample surfaces were observed with a particle size of about $0.1-0.5 \mu \mathrm{m}$ in diameter. In addition, there are particle clusters that are typically several microns in diameter randomly distributed on the surface. EDX compositional data (Table 8) indicated that the particles are oxides of aluminum.

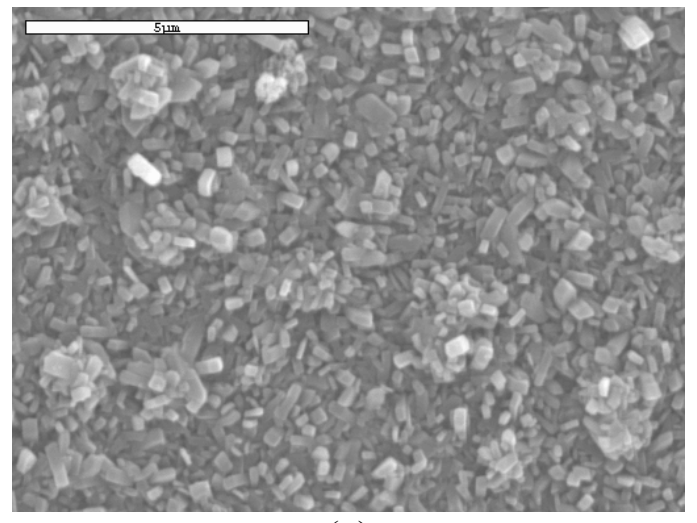

(a)

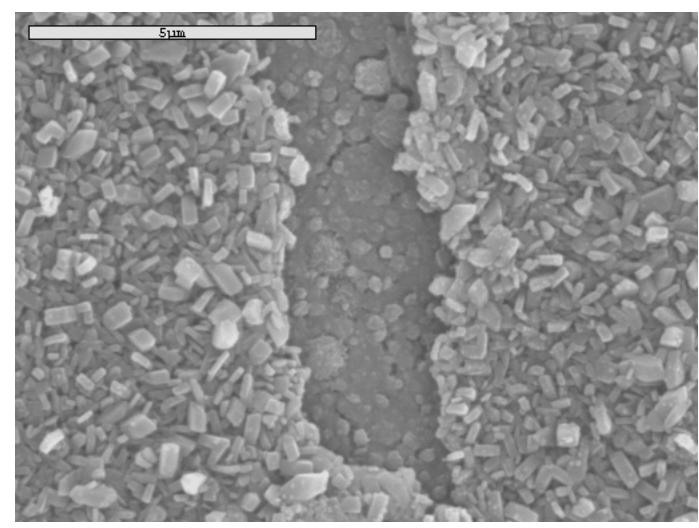

(b)

Figure 39: SEEM micrographs of a sputter deposited alumina film on Zircaloy after autoclave exposure for 24 hours. The alumina film was annealed at (a) $550^{\circ} \mathrm{C}$ and (b) $650^{\circ} \mathrm{C}$, respectively, for 2 hours. 
(a)

(b)

\begin{tabular}{|lcc|lcl|}
\hline Element & $\begin{array}{c}\text { Spect. } \\
\text { type }\end{array}$ & $\begin{array}{c}\text { Atomic } \\
\%\end{array}$ & Element & $\begin{array}{c}\text { Spect. } \\
\text { type }\end{array}$ & $\begin{array}{c}\text { Atomic } \\
\%\end{array}$ \\
\hline $\mathrm{O} \mathrm{K}$ & $\mathrm{ED}$ & 72.58 & $\mathrm{O} \mathrm{K}$ & $\mathrm{ED}$ & 71.58 \\
$\mathrm{Al} \mathrm{K}$ & $\mathrm{ED}$ & 22.67 & $\mathrm{Al} \mathrm{K}$ & $\mathrm{ED}$ & 22.93 \\
$\mathrm{Zr} \mathrm{L}$ & $\mathrm{ED}$ & 4.74 & $\mathrm{Zr} \mathrm{L}$ & $\mathrm{ED}$ & 5.49 \\
\hline \multicolumn{3}{|c|}{ Total } & 100.00 & \multicolumn{3}{c|}{ Total } & 100.00 \\
\hline
\end{tabular}

Table 8. EDX compositional analysis of the alumina film after annealed at (a) $550^{\circ} \mathrm{C}$ and (b) $650^{\circ} \mathrm{C}$ for $2 \mathrm{hr}$.

\section{Economic analysis of a potential commercial process for coating full length Zircaloy-4 clad tubes with $\mathrm{SiC}$}

MER corporation, a USA company extensively involved in coating processes of ceramics was asked to carry out an economic analysis of a process involving coating 1.5 million tubes per year with SiC by a PACVD process. Table 9 summarizes their cost analysis for a commercial process for coating full-length $(\sim 12 \mathrm{ft}$.) Zircaloy-4 Clad tubes with $\mathrm{SiC}$. They determined that a commercial facility could carry out the coating at a cost of $\sim \$ 42$ per tube. A zircaloy tube costs approximately $\$ 100$, so this process would result in approximately $40 \%$ increase in tube cost.

\begin{tabular}{|c|c|c|}
\hline Item & $\mathbf{\$ p e r}$ tube & percentage \\
\hline Direct Labor & $\$ 10.81$ & $26 \%$ \\
\hline $\begin{array}{c}\text { Variable Costs } \\
\text { Ceprecital }\end{array}$ & $\$ 5.49$ & $13 \%$ \\
\hline Maintenance & $\$ 5.33$ & $13 \%$ \\
\hline OH Allocation & $\$ 13.77$ & $10 \%$ \\
\hline $\begin{array}{c}\text { Cost of Capital at } \\
10 \%\end{array}$ & $\$ 2.71$ & $63 \%$ \\
\hline Grand Total & $\$ 42.16$ & \\
\hline
\end{tabular}

Table 9: Delivered cost per tube coated with SiC. 
Expended Versus Budgeted: Zircaloy Cladding Research Project

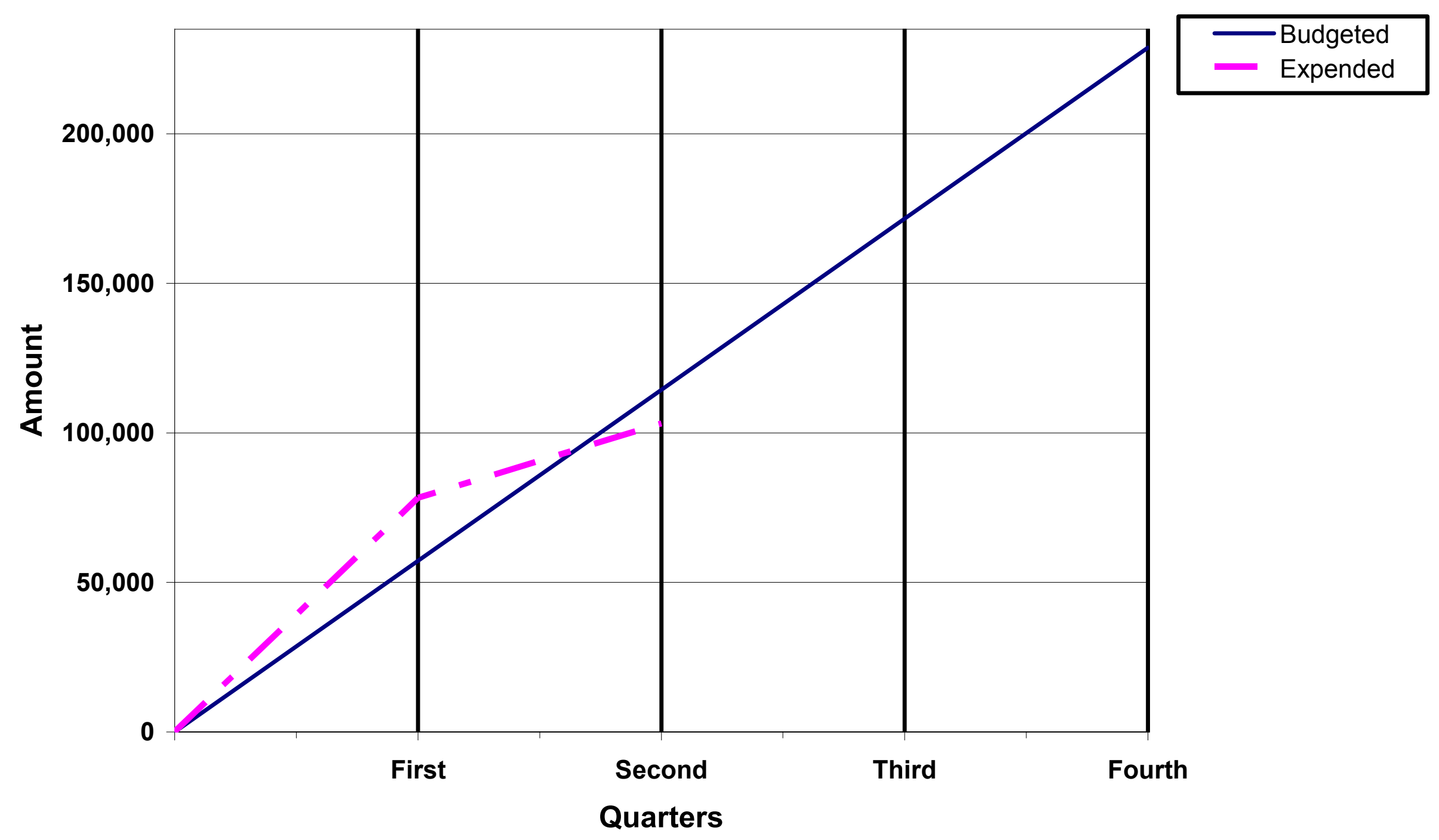

